\title{
Las ciudades andaluzas en el siglo XIX. Territorio y desarrollo
}

Gabriel CANO GARCÍA*

\section{RESUMEN}

Dos tercios de la población andaluza viven en ciudades con más de 20.000 habitantes, que forman un sistema bastante bien distribuido, lo que redunda en beneficio de una mejor articulación del territorio. Esta red urbana cuenta con amplios antecedentes y en este artículo se analiza la situación en el siglo XIX, hito importante, como una parte de un estudio más amplio hasta la situación actual.

\section{ABSTRACT}

Two thirds of the population in Andalusia live in cities with more than 20.000 inhabitants, making up a well laid out system that, in this way, contribute to the create a better joint of the territory. This urban network has detailed records and this article develops the situation in the XIX century, important milestone, as part of a full study that analyses the situation until nowadays.

${ }^{*}$ Catedrático de Análisis Geográfico Regional y Director del I.D.R., donde se ha realizado este artículo. Quiero agradecer la colaboración de Ana Román (elaboración de datos censales), Susana Vélez (cartografía), Isabel Barrera (maquetación) e Ignacio Miró (corrección de textos). 


\section{INTRODUCCIÓN}

Este trabajo (que forma parte de otro más amplio sobre ciudades andaluzas) pretende dos objetivos principales: primero, el conocimiento de la red urbana en nuestra Comunidad en un momento importante, como es a mediados del XIX, para comprender la evolución de un sistema (que cuenta con antecedentes tan lejanos, como la época de la Bética romana y al-Ándalus) que hoy presenta una interesante distribución y caracterización. Veinte siglos de una presencia urbana, percibida y hasta elogiada en numerosos escritos, si bien en la historia hay de todo, auges y decadencias, que, lógicamente, afectan también a las ciudades. El crecimiento demográfico es casi continuado (otra cosa son las funciones), aunque también hay regresiones (Córdoba y Granada, por ejemplo) y reconversiones (tras la pérdida del comercio con América, se impulsan otros sectores, como es el caso de Sevilla, Málaga y Cádiz), además de la crisis emigratoria del siglo pasado, que afecta también a las ciudades medias.

El siglo XIX cuenta con unos censos oficiales que permiten observar el transcurso estadístico y que, sobre todo, dan pie a elaborar un aparato cartográfico para entender esa evolución. El año 1787 marca el inicio de lo que será la centuria y el de 1842 coincide con una obra magna, el Diccionario de Madoz, 1845-50, en el que aparecen por orden alfabético todos los municipios con información suficiente (actividades económicas, producciones, agricultura, industria, comercio, etc.) para situar las funciones de pueblos y ciudades. Sobre las características de esta publicación hay algunos escritos, como las introducciones a la edición de las ocho provincias andaluzas, citadas en la Bibliografía.

El segundo objetivo anunciado estriba en introducir algún elemento metodológico, dado que es discutible, y discutido, cuáles son los límites de lo que puede considerarse ciudad. A este particular, ensayaremos con datos, cartografía $y$, sobre todo, el conocimiento de la situación urbana para proponer algunas adaptaciones a esos límites, en relación con la población total del sistema, como hipótesis. En el censo de 1842, cuyas cifras utilizaremos en este trabajo, la población era de 2.300.020, que, comparada con las del 2005, resultan los límites del cuadro siguiente, redondeados según se indica. 


\begin{tabular}{|c|c|c|c|c|}
\hline \multicolumn{3}{|c|}{ Cuadro 1. Posibles límites urbanos según la población de Andalucía } \\
\hline Año & Población & \multicolumn{3}{|c|}{ Límites e Intervalos Urbanos } \\
\hline 1842 & 2.300 .020 & 6.000 & 10.000 & 15.000 \\
\hline 2005 & 7.849 .799 & 20.000 & 30.000 & 50.000 \\
\hline
\end{tabular}

La dimensión territorial en el pasado era más nítida por la oposición ciudadcampo, incluso marcada por murallas, derribadas total o parcialmente en el segundo tercio del XIX. Pero hoy la apreciación urbana es distinta, al existir aglomeraciones de municipios grandes, medianos y pequeños 0 , por potro lado, espacios en los que no existen grandes, ni a veces pequeños, centros articuladores. Eso es lo que estudiamos en 1987, 2000 y 2002 (Geografía de Andalucía, Gran Enciclopedia Andaluza y Comarcas Andaluzas, respectivamente) y que ahora intentaremos cotejar con otras épocas de nuestro sistema urbano.

\section{LAS CIFRAS DEL CRECIMIENTO}

Conviene plantear las cifras y sus explicaciones considerando lo posterior al XIX, al menos en sus notas básicas, para enmarcar mejor el período que ahora nos interesa, empezando por rasgos generales actuales. Casi dos tercios de la población andaluza vivían en el 2005 en municipios de más de 20.000 habitantes, tras un considerable aumento (en 1950 no llegaba a la mitad, apenas sobrepasada en 1970), según puede observarse en el cuadro 2. Si nos vamos hacia atrás, las distancias con 1842 (hace 163 años) son respectivamente de 48.3 puntos de porcentaje y 4.734 .919 habitantes (en el 2006, 8 millones en total). Y, si no fijamos en el primer censo, 1787, la población andaluza residente en municipios con más de 20.000 habitantes era 420.000 , frente a los más de 5 millones de ahora. Aun así, habrá que relacionar con la cifra total andaluza y bajar el límite de los 20.000 en épocas anteriores, como apuntábamos antes.

El aumento demográfico también ha sido alto (una ganancia de 36 puntos) en los municipios mayores de 50.000 en los últimos cien años, pues en ellos se concentra ahora la mitad de la población andaluza, cuando en 1970 era el 36 \% y sólo el 14.4 en 1910 (Sevilla, Málaga, Granada, Cádiz, Córdoba y Jerez). No podemos ir tan atrás para ver el incremento de los mayores de 100.000 (en 1842 sólo Sevilla), habiéndose pasado de un $7.6 \%$ de la población andaluza a principios del XX (Sevilla y Málaga) al 
37.5 de 2005 (las ocho capitales más Jerez, casi 200.000, Marbella, Dos Hermanas y Algeciras). Las capitales han aumentado menos (12.4 puntos de porcentaje, desde el 18.1 de 1787 al 30.5 de hoy), si bien en 1991 el peso era mayor, porque, como se sabe, los que más crecen últimamente son los municipios de la periferia de las grandes ciudades.

\section{Cuadro 2. Evolución del peso demográfico relativo en municipios con más de 20.000 (\%)}

\begin{tabular}{|l|l|l|l|l|l|}
\hline Más de & 1787 & 1842 & 1910 & 2005 & Dif. Puntos \\
\hline $\mathbf{2 0 . 0 0 0}$ & 22.7 & 16.7 & 25.0 & 65.3 & 42.6 \\
\hline $\mathbf{5 0 . 0 0 0}$ & 14.0 & 12.4 & 14.4 & 50.0 & 36.0 \\
\hline $\mathbf{1 0 0 . 0 0 0}$ & 0.0 & 4.4 & 7.6 & 37.5 & 37.5 \\
\hline Dif. ptos 100-20 & 22.7 & 12.6 & 17.4 & 27.8 & \\
\hline Capitales & 18.1 & 16.5 & 15.9 & 30.5 & 12.4 \\
\hline
\end{tabular}

Para tener una referencia de los aumentos de los núcleos superiores a 20.000h., comparamos con las variaciones de la población total (cuadro 3), y las principales conclusiones son un mayor crecimiento de las ciudades en todo los casos, excepto entre 1787 y 1842, debido a la dispersión existente por una mayor explotación agraria, mientras que las deficiencias de comunicación requieren centros y radios de acción más próximos. Después, la primera mitad del XX es la de más alta urbanización (o retroceso rural), mientras que 1950-70 es la etapa más fuerte de emigración, con un escaso incremento medio anual del censo, pero un cierto desplazamiento a las ciudades. Hasta 1991 existe una recuperación, y posteriormente también, pero la diferencia entre población total y urbana disminuye, por la periferización metropolitana aludida antes.

Cuadro 3. Porcentajes de crecimiento de ciudades con más de 20.000 h. y de la población total andaluza (\%)

\begin{tabular}{|c|c|c|c|c|c|c|c|c|c|c|}
\hline \multirow[b]{2}{*}{ Más 20.000} & \multicolumn{2}{|c|}{$1991-2005$} & \multicolumn{2}{|c|}{$1970-1991$} & \multicolumn{2}{|c|}{$1950-1970$} & \multicolumn{2}{|c|}{$1910-1950$} & \multicolumn{2}{|c|}{$1787-1842$} \\
\hline & 19.0 & 1.36 & 37.5 & 1.78 & 28.5 & 1.42 & 158.3 & 3.96 & -7.4 & -1.3 \\
\hline Pob. Total & 13.1 & 0.93 & 11.9 & 0.57 & 6.1 & 0.30 & 48.6 & 1.21 & 24.3 & 0.44 \\
\hline Diferencia & 5.9 & 0.43 & 25.4 & 1.21 & 22.4 & 1.12 & 109.7 & 2.75 & 31.7 & 0.57 \\
\hline
\end{tabular}

El primer porcentaje se refiere a todo el período y el segundo, a la media anual. 

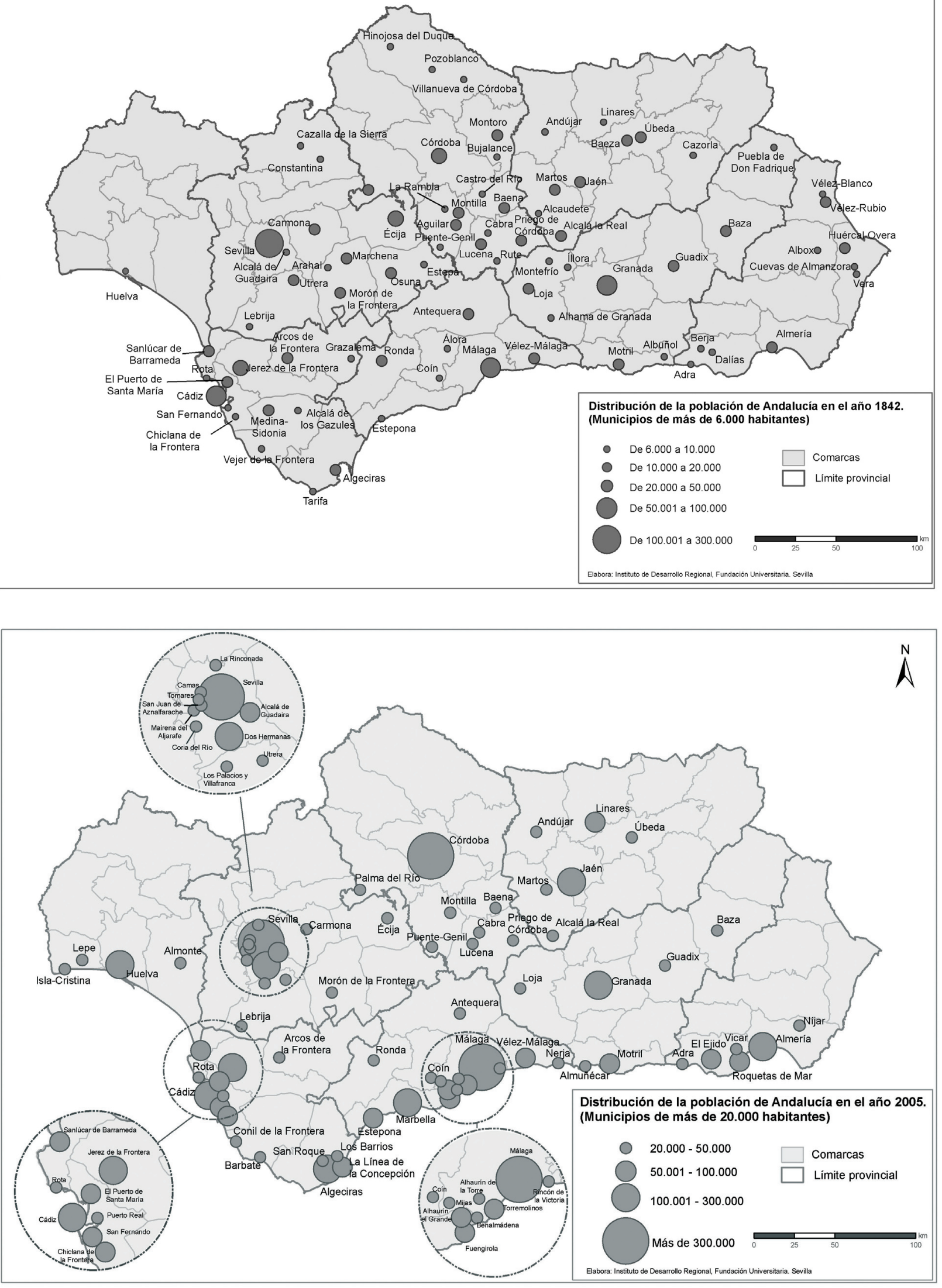
Los sistemas urbanos no son iguales en todas las provincias, hecho que veremos después; pero interesan ahora unas pinceladas evolutivas según tres variables: el peso de la capital, la relación de ésta con la segunda ciudad y el porcentaje de municipios mayores de $20.000 \mathrm{~h}$. (cuadro 5). Sobre lo primero, la pauta andaluza es de disminución en el XIX (1787-1910, $18.5 \%$ al 15.9), aumento continuo hasta 1991 (33.4 \%), estancamiento hasta 2001 y bajada (30.5\%) en el 2005. Y los modelos provinciales no difieren de esa evolución (otra cosa es el peso específico en cada caso; Córdoba y Cádiz $41 \%$ y $11.2 \%$, respectivamente, en el 2005). Pero pueden destacarse el incremento de Huelva en 1842 por el establecimiento de la capitalidad provincial, la disminución anticipada de Almería (entre 1970 y 1991) por el rápido ascenso de El Ejido y Roquetas, y el pequeño aumento final de Córdoba y Jaén, con menos competencia de núcleos próximos y extensos términos, sobre todo la primera.

Los cambios de la segunda ciudad de cada provincia son significativos de la distribución: sólo en Cádiz y Córdoba se mantienen (Jerez y la industrial Lucena), mientras que en Málaga y Granada pasan del interior, fundamentalmente agrario (Antequera, Loja y Guadix) a la costa (Vélez Málaga, Marbella y Motril). En Sevilla se traslada el peso demográfico de la campiña (Écija) al área metropolitana capitalina (Dos Hermanas); el auge minero e industrial colocan a Linares por delante de Alcalá la Real y Úbeda, y, por último, Almería y Huelva acusan la perificidad, la escasez de núcleos y la reciente expansión agraria y turística, terminando por ser la segunda ciudad en estas provincias El Ejido y Lepe, respectivamente, tras distintas localizaciones (cuadro 4). Esto enmarca el XIX, en el que los cambios son mínimos: Huelva (Moguer, Zalamea) y Jaén (Alcalá, Úbeda, Linares) por la minería, y Almería también por agrupaciones municipales.

La relación cuantitativa entre la primera y la segunda urbe provincial difieren bastante: del índice 0.7 Cádiz-Jerez a 8.1 Córdoba-Lucena en el 2005, con una evolución de continua separación, o, lo que es igual, de mayor incremento capitalino (excepto Cádiz, pequeña "isla" de espacio saturado hace tiempo), con picos de máximos en 1970 (Almería, Granada, Málaga y Sevilla) o 1991 (Córdoba y Huelva);por 
su parte, Cádiz y Jaén han tenido un recorrido de bajada y subida, en cada una, mas regular y moderado.

\begin{tabular}{|c|c|c|c|c|c|c|c|c|c|c|}
\hline & & Almería & Cádiz & Córdoba & Granada & Huelva & Jaén & Málaga & Sevilla & Andalucia \\
\hline \multirow[t]{4}{*}{1787} & \%capital & 9.3 & 23.2 & 15.1 & 20.9 & 4.6 & 8.3 & 20.7 & 26.7 & 18.5 \\
\hline & $2^{\mathrm{a}}$ ciudad & H.Overa & Jerez & Lucena & Loja & Moguer & A. Real & Antequera & Écija & \\
\hline & $1^{\mathrm{a} / 2^{\mathrm{a}}}$ & 1.8 & 1.6 & 6.6 & 5.0 & 0.9 & 1.4 & 2.5 & 2.8 & 1.6 \\
\hline & Más 20.000 & 0.0 & 47.3 & 15.1 & 20.9 & 0.0 & 0.0 & 29.0 & 36.4 & 22.7 \\
\hline \multirow[t]{4}{*}{1842} & \%capital & 7.1 & 19.0 & 13.7 & 16.6 & 12.8 & 7.1 & 20.2 & 27.2 & 16.5 \\
\hline & $2^{a}$ ciudad & H.Overa & Jerez & Lucena & Loja & Moguer & Úbeda & Antequera & Écija & \\
\hline & $1^{a} / 2^{a}$ & 1.4 & 1.6 & 2.5 & 4.1 & 3.1 & 1.3 & 4.0 & 4.2 & \\
\hline & Más 20.000 & 0.0 & 30.7 & 13.7 & 16.6 & 0.0 & 0.0 & 20.1 & 33.6 & 16.7 \\
\hline \multirow[t]{4}{*}{1910} & \%capital & 12.0 & 15.0 & 13.2 & 15.2 & 9.6 & 5.4 & 25.6 & 25.9 & 15.9 \\
\hline & $2^{a}$ ciudad & C. Vera & Jerez & Lucena & Loja & Zalamea & Linares & Antequera & Écija & \\
\hline & $1^{a} / 2^{a}$ & 1.8 & 1.1 & 3.1 & 4.2 & 2.4 & 0.8 & 4.2 & 6.6 & \\
\hline & Más 20.000 & 19.0 & 46.0 & 18.0 & 15.0 & 10.0 & 17.0 & 41.0 & 30.0 & 25.0 \\
\hline \multirow[t]{4}{*}{1950} & \%capital & 21.0 & 14.2 & 20.3 & 19.5 & 17.0 & 7.8 & 36.3 & 34.0 & 22.4 \\
\hline & $2^{\mathrm{a}}$ ciudad & H.Overa & Jerez & Lucena & Guadix & I. Cristina & Linares & Antequera & Écija & \\
\hline & $1^{a} / 2^{a}$ & 5.4 & 0.9 & 4.4 & 5.1 & 5.7 & 1.2 & 6.3 & 9.0 & \\
\hline & Más 20.000 & 21.0 & 63.0 & 45.0 & 33.0 & 17.0 & 35.0 & 53.0 & 54.0 & 43.2 \\
\hline \multirow[t]{4}{*}{2005} & \%capital & 29.7 & 11.2 & 41.0 & 27.5 & 30.0 & 17.7 & 38.4 & 38.8 & 30.5 \\
\hline & $2^{a}$ ciudad & El Ejido & Jerez & Lucena & Motril & Lepe & Linares & Marbella & Dos Hermanas & \\
\hline & $1^{a} / 2^{a}$ & 2.6 & 0.7 & 8.1 & 4.2 & 6.4 & 1.9 & 4.5 & 6.3 & \\
\hline & Más 20.000 & 63.0 & 82.0 & 63.0 & 44.0 & 43.0 & 45.0 & 83.0 & 69.0 & 65.3 \\
\hline
\end{tabular}

Sobre los municipios mayores de 20.000 , el proceso general es de disminución (como en el caso de la capitalidad) entre 1787 y 1842, y después, de continua subida, lo que en general aparece siempre con pequeños matices, que dejamos para aportaciones posteriores. Antes, se ofrecen algunos ejemplos de crecimientos espectaculares recientes en ciertos lugares, que nos van a dar pistas sobre la distribución actual. Porque, como se ve en el cuadro 5, se trata de capitales, periferias metropolitanas (Mairena del Aljarafe o Tomares), litoral turístico (Benalmádena, Roquetas) o núcleos de agricultura intensiva (El Ejido); si bien existe, por lo general, una mezcla de funciones. 


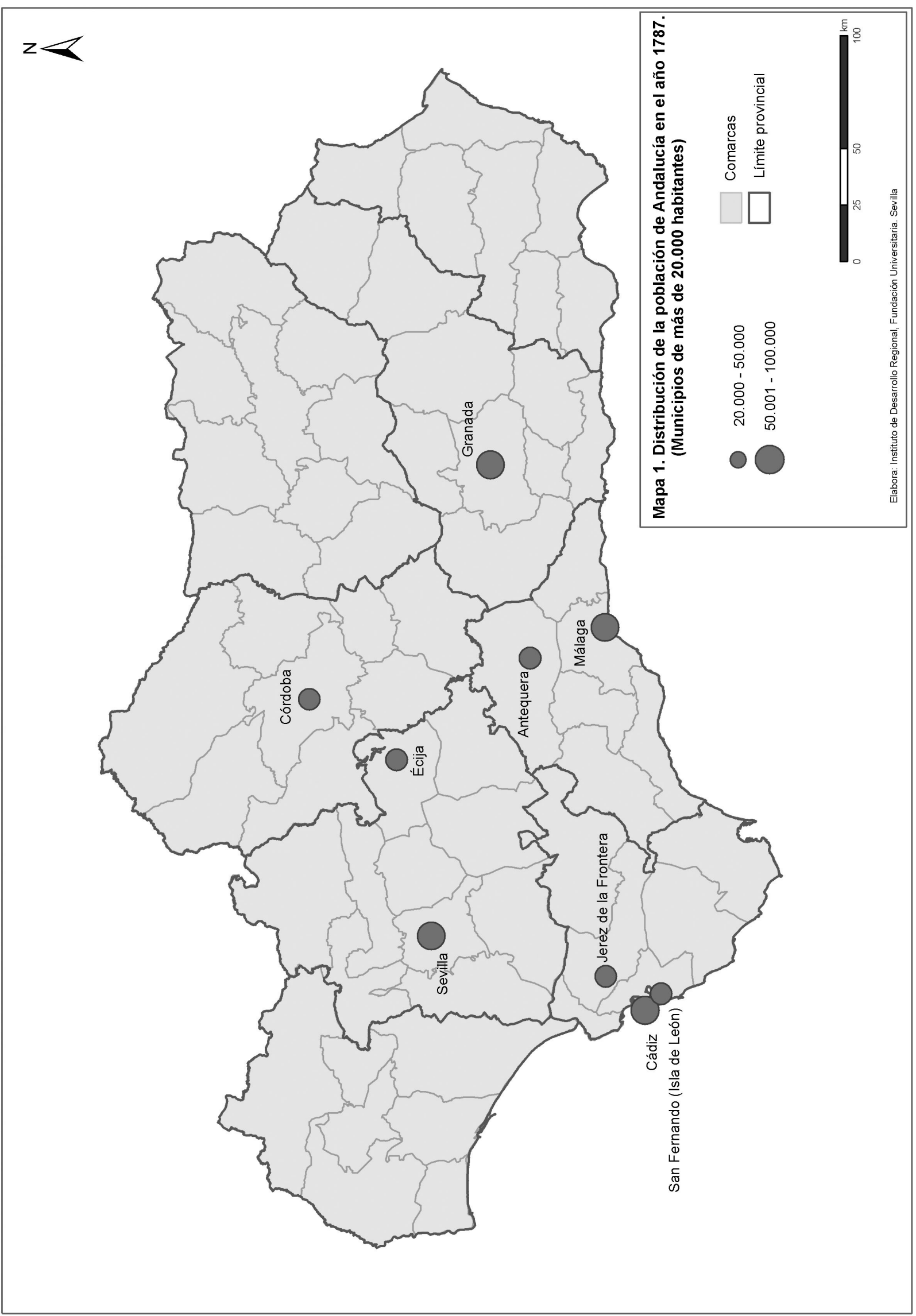




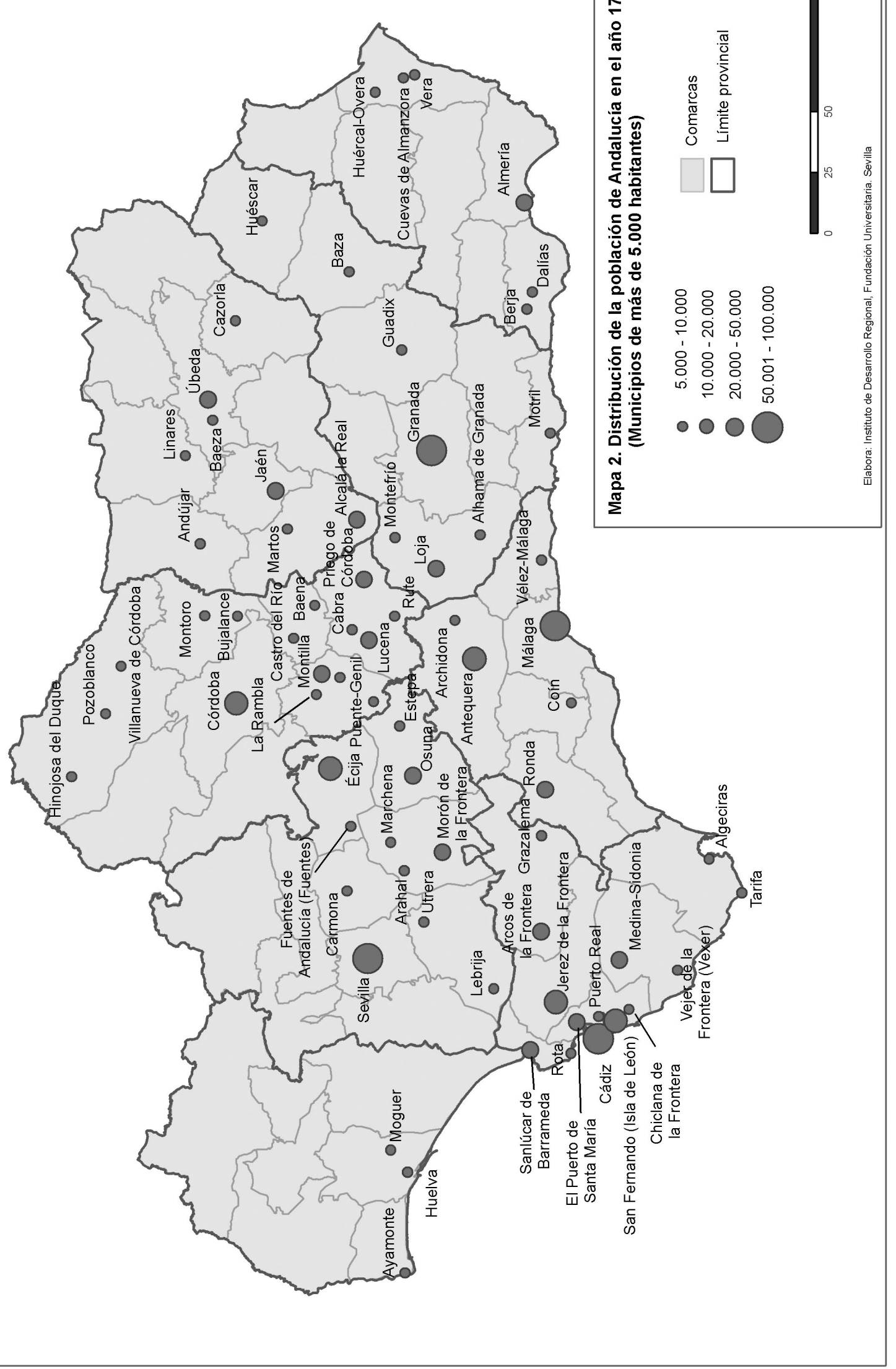




\begin{tabular}{|l|c|c|c|c|}
\hline \multicolumn{7}{|c|}{ Cuadro 5. Evolución de algunos municipios } \\
\hline & 1910 & 1970 & 2005 & $\%$ en 1910-2005 \\
\hline El Ejido & 8.006 & 21.304 & 68.828 & 760.3 \\
\hline Roquetas del Mar & 2.840 & 12.884 & 65.886 & 2.219 .9 \\
\hline Huelva & 28.357 & 96.347 & 145.150 & 411.8 \\
\hline Benalmádena & 1.863 & 6.633 & 45.686 & 2.356 .0 \\
\hline Mairena Aljarafe & 1.356 & 3.753 & 38.770 & 2.751 .0 \\
\hline Tomares & 886 & 3.810 & 20.127 & 2.171 .7 \\
\hline
\end{tabular}

\section{LAS CIUDADES A PRINCIPIOS DEL XIX}

Entonces predominaba la agricultura, pero existían, por otra parte, actividades industriales, mineras, mercantiles, etc., y los servicios capitalinos. Éstos adquieren una institucionalización desde la provincialización de 1833, aunque existían anteriormente en las cabeceras de los antiguos cuatro reinos (Sevilla, Granada, Córdoba y Jaén), más Cádiz y Málaga, desde el desarrollo comercial y marítimo del XVIII. También otras ciudades cuentan con ciertos servicios de administración y justicia, especialmente desde la creación de los partidos judiciales en 1834. Y precisamente en el mapa de 1787 (número 1) sólo hay cuatro ciudades con más de 50.000 habitantes (evilla, 80.915; Cádiz, Granada y Málaga, 51.098) y cinco que pasan de los 20.000 (Jerez, 45.506; Córdoba, Écija, Isla de León y Antequera, 20.266). Esto viene a destacar a las dos grandes ciudades tradicionales, Sevilla y Granada, la consolidación y avance portuario (Cádiz y Málaga), y la presencia de dos grandes agrociudades cabeceras de comarca (Jerez y Écija), más otra importante, Antequera; mientras que la Isla de León obedece a la instauración de un núcleo militar. Córdoba revela una cierta crisis, Jaén está por debajo del límite de veinte mil, así como las otras dos capitales de 1833 (Almería y Huelva). De esta manera, los primeros lugares del sistema urbano de finales del XVIII son muy distintos al actual, tanto en la presencia (además de los casos citados, no están otras como Algeciras o Marbella) como en el orden (actualmente Málaga es la segunda y no la cuarta). Eran grandes centros tradicionales con múltiples funciones (agraria, industria, servicios administrativos, comercio...) y con un vacío de toda la periferia: provincias de Almería, Jaén y Huelva, y el norte de Granada, Córdoba y Sevilla.

Pero, si se incluyen los núcleos con más de 10.000 (mapa 2) aparecen Almería, Jaén, el inicio de la conurbación gaditana y toda una serie de cabeceras comarcales: Úbeda, Alcalá la Real, Loja, Priego, Lucena, Montilla, Marchena, Morón, Ronda, Arcos 
y Medina Sidonia, que entonces eran verdaderos centros y agrociudades. Incluso, si incorporamos los mayores de 5.000 (que, como dijimos, sería el equivalente a los 20.000 de ahora, según la evolución de la población total andaluza), se refuerzan ámbitos. Concretamente, centros de cierta importancia para entonces, y se aprecia una buena distribución en Granada, Jaén, Málaga (excepto la despoblada Costa del Sol) y las Sierras del Campo de Gibraltar. Sevilla presenta (además del vacío marismeño) falta de núcleos en la Sierra Norte, al igual que sucede en Córdoba; como también en las montañas almerienses de María, Estancias y Filabres. La provincia de Huelva sólo tiene tres núcleos costeros con menos de 10.000 habitantes, y el resto está desarticulado, como toda Sierra Morena (excepto los Pedroches, Hinojosa, Pozoblanco y Villanueva).

\section{LA CABECERA DEL SISTEMA EN EL MAPA DE 1842}

\subsection{Introducción}

En estas fechas se hace el segundo censo moderno (las cifras de 1800 son estimaciones) y una magna obra, el Diccionario de Madoz, donde consta una detallada información, que precisamente hemos manejado para elaborar una parte de la Gran Enciclopedia Ilustrada de Andalucía, desde 2004, y que ahora, con un enfoque distinto, podremos aprovechar parcialmente en este artículo. Hay además unas introducciones de los ocho tomos provinciales publicados en 1988 por las Editoriales Andaluzas Unidas.

La población pasa de 1.850.157 a 2.300.020 entre los dos censos (1787-1842), casi medio millón más, el $24.3 \%$, pero en 55 años, lo que supone un crecimiento anual medio de 4 por mil, que indica emigración y no es de los más alto de la evolución demográfica andaluza. Y esto es así, ya que los incrementos naturales (en torno al 10 por mil) no eran mayores que los de los sesenta del XX, porque, aunque la natalidad era muy alta (más del 40 por mil, hoy en torno al 11), también lo era la mortalidad (superior al 30 , actualmente el 8). 
Suele afirmarse que el aumento poblacional se acumula en la parte alta del sistema, lo interesante es saber si es siempre así, en qué medida y su distribución. Como puede verse en el cuadro 2, los municipios mayores de $20.000 \mathrm{~h}$. (incluyendo los más de cincuenta y cien mil) eran el 16.7 de la población total, cuando en 1787 suponían el 22.7. Y, si se toman los límites de 6.000 y 5.000 , respectivamente, también han bajado (50.8 y 46.9, cuadro 2), al igual que el peso de las capitales, disminuyendo la distancia entre éstas y la segunda ciudad, excepto en las dos grandes (Sevilla y Málaga) y Huelva, que crece extraordinariamente tras sus estatus de capitalidad en 1833. Ello se debe a la regresión de dos ciudades: San Fernando y Antequera. La primera tuvo más de 28.000 en 1787 , luego de convertirse en una localidad para el servicio militar, y la segunda (sobrepasa los 20.000 en el primer censo y se queda en 17.000 en 1842) sufre una fuerte competencia de la agricultura, industrialización y comercio de la costa, especialmente de Málaga. Pero, si ambas se hubieran mantenido, el porcentaje superior a 20.000 hubiera subido 2 puntos, quedando aún cuatro por debajo de 1787, lo que significa que hay mayor crecimiento proporcional en núcleos más pequeños, seguramente por la expansión agraria.

Así, la parte alta del sistema se reduce a siete núcleos y experimenta una notable modificación. Sevilla se separa del conjunto al sobrepasar los cien mil (100.498), Málaga ocupa el segundo lugar del ranking, desplazando a Cádiz, que también es superada por Granada; es decir, que la crisis del comercio y la reducida superficie gaditana ceden ante la capitalidad, lo que ocurre también en Córdoba y Jerez por razones algo diferentes. La ciudad califal destaca poco en el Madoz y, por otra parte, Huelva no llega a los 10.000 (poco más de 7.000), mientras que Almería y Jaén se acercaban a los 18.000 y, en cambio, Écija, ciudad histórica, contaba con 23.722. A continuación trazamos unos rasgos de las principales ciudades.

\subsection{Sevilla}

Era la principal ciudad de Andalucía y no sólo por población, sino también por funciones administrativas sobre todo, pues recordemos que hasta la provincialización de 1833 era la capital de un extenso reino, heredero territorial de la época almohade, siglo XIII, que abarcaba aproximadamente las actuales provincias de Sevilla, Huelva y Cádiz, más otras zonas como la comarca de Antequera. $Y$ en buena medida esa circunscripción se mantenía a mediados del XIX (y después), incluso con el añadido de Córdoba, pues las cuatro formaban la Audiencia Territorial, con más de 
un millón de habitantes, y la Capitanía General, con diez cuarteles en Sevilla. La división eclesiástica la hacía sede de un extenso Arzobispado, que incluía Canarias, y era también centro del Tercio Naval (dentro del Departamento de Cádiz, con subdelegaciones en Alcalá del Río y Tablazo), capital provincial, de Intendencia (con tres partidos administrativos: Sevilla, Écija y Osuna) y de partido judicial.

El comercio, "que un día tuvo grande importancia en sus relaciones con América, ha cambiado completamente de aspecto, y sin ocuparse de aquellas operaciones más lucrativas...las ha dado una extensión (espacio) mucho mayor..." (MADOZ, 1845). Es decir, que tras el traslado de la Casa de Contratación, la perdida del monopolio y la independencia americana, el comercio disminuye considerablemente y "la exportación se reduce a muy poco. Principalmente azogue, plomo, cobre, aceite de oliva, lana, naranjas, regaliz en pasta y en rama, corcho y rara vez algunos cereales", por lo que no se hacían grandes operaciones mercantiles, ni se había establecido la banca. Pero sí existía un Martillo o mercado público mayorista y, también, algunas sociedades importantes, "formadas por capitalistas", como la Compañía del Guadalquivir, con el empeño de volver a hacer navegable el Río Grande hasta Córdoba o la de Seguros de incendios.

La industria era considerable, especialmente la militar (fundiciones, pirotecnia, Maestranza de Artillería, fábricas de pólvora y salitre...) y de tabacos (4.549 personas, 3.500 cigarreras, en 1849), pero también los astilleros, la fábrica de loza de la Cartuja, con unos 400 operarios, la siderurgia y fabricación de maquinarias, (sobre todo, la fundición de San Antonio, que competía bien con el hierro vizcaíno, BERNAL, 1988), varias industrias textiles con más de mil empleados (algodón, lana, seda, hilo) y otras (cristales, curtidos, extracto de regaliz, abundante en las vegas...). Y precisamente la actividad agraria no era desdeñable, así como las ferias y mercados de animales. En realidad, Sevilla y Málaga representan los inicios de una industrialización andaluza en las dos especialidades motores de la revolución industrial (comenzada en Inglaterra en el XVIII, la textil y siderúrgica) y del crecimiento urbano.

\subsection{Málaga}

Y efectivamente, Málaga no tenía la función administrativa de Sevilla, pero la industria y el comercio hacían de ella un potente núcleo. En el Diccionario de Madoz se resaltan las fundiciones "La Constancia" de Marbella, 1826, y Málaga, 1833, con 
importantes maquinarias (entre otras, tres grandes hornos de 50 pies de alto) y unos 2.500 operarios, más los empleos indirectos de transporte, leña, carbón, etc. Había otros dos importantes establecimientos fabriles: uno de productos químicos, y otro de hilados y tejidos (Industria Malagueña). Y Málaga era el centro comercial de toda la provincia (aunque los caminos no estaban todavía en buenas condiciones) y por el puerto salían productos y hierro refinado de Málaga y Marbella, con una balanza comercial aduanera favorable, próxima a los dos millones de reales (LACOMBA, 1988). Pero el mismo autor califica de frugal esta situación, que se resume en una fuerte expansión de la vid a finales del XVIII, se desarrolla el comercio en el mejorado puerto y se perfila una burguesía mercantil, en parte extranjera. El primer tercio del XIX contempla avances y retrocesos, y el segundo es de auge, con una fuerte industrialización (la segunda del Estado, tras Barcelona) y tráfico comercial; mientras que la última parte del XIX es de crisis y fuerte decadencia, cuyas causas no están totalmente explicadas, en nuestra opinión.

\subsection{Granada}

La tercera ciudad andaluza ejerce funciones administrativas parecidas a Sevilla, pero carece de su industria y comercio. También fue hasta 1833 capital de un reino (espacio heredado del estado nazarita), comprendiendo aproximadamente las tres provincias actuales de Granada, Almería y Málaga. Centraba Audiencia Territorial, Capitanía General, Arzobispado, capital provincial, de Intendencia y de partido judicial. Y, como Sevilla, tenía una importante Universidad, pero la base de la economía no era la industria, sino la agricultura de la vega, cuyos regadíos se reconocen en el Diccionario de Madoz de origen árabe, produciendo "toda clase de granos, aceite, vino, alguna seda, pocos agrios, muchas frutas y legumbres, lino, cáñamo, avellanas y alguna madera de construcción". Se exportaban los excedentes por Málaga y Levante, y se esperaba la terminación del camino a Motril para embarcar por ese puerto. La elaboración de seda había decaído desde hacía tiempo y, sobre todo, por el incendio de la Alcaicería de 1843, aunque se notaba cierta recuperación y el refuerzo del lino y cáñamo. A ello se unía alguna otra industria de lana, la alfarería y poco más. La dificultades viarias para el transporte de mercancías (las líneas de diligencias iban a Madrid, Málaga, Almería, Córdoba y Sevilla) y la baratura de las producciones no favorecían la economía de Granada. Ésta tampoco tenía una feria "tan general y célebre como la de Mairena, Ronda o Loja, o como la reciente concedida a Sevilla, donde concurren ganados de todas las especies", pero en ella sí había un mercado anual en el Triunfo. 


\subsection{Cádiz}

Tras la pérdida del monopolio y el comienzo de la independencia de las colonias americanas, el otrora emporio comercial decae y el Diccionario de Madoz, de 1845, ya refleja una situación muy distinta a la del siglo XVIII. En efecto, la población había descendido, a 53.922 (con un "inmenso número de brazos, hoy parados, que anhelan trabajo"). Sin embargo, la industria y las artes "van tomando un vuelo bastante rápido", muebles de calidad, joyas y alhajas, sombreros, guantes ("que surten a Londres y otros puntos"), cantería, tejidos, sobre todo de algodón, con más de 500 telares y otras fabricaciones. "Todas las artes e industria tienen vida" aquí, dado que...."su comercio, rico y opulento en otra época, ha quedado reducido casi al de cabotaje,"..."goza de comodidades y vive con lujo y boato en el exterior". Se ven en Cádiz "dos poblaciones distintas, una la comercial e industrial, otra la puramente doméstica; la primera habita los bajos de las casas, la segunda lo alto, y así hasta cierta hora de la noche, están casi todas las calles iluminadas como en una gran feria“. Y después se cita para corroborar esa afirmación que hay 9 cafés, 15 fondas, 513 tiendas de comestibles y vinos, aparte de platerías, boticas, etc., y una larga lista de oficios y trabajos.

Como señala SUÁREZ JAPÓN, 1988, la fundición existente y la construcción de una gran fábrica de tejidos, que se anuncia movida por vapor, indica una mecanización, que se une al progreso científico y cultural desde el XVIII. La reconversión, pues, económica y del uso de las viviendas, tras la crisis portuaria, se corrobora observando en el Diccionario las principales mercancías entradas desde el extranjero en 1843 y 1844, que hablan de materias primas para la industria: maquinarias, mil quinientas herramientas, hojalata (40 toneladas), dos millones y medio de duelas para barriles, alambres, cueros al pelo (unas 800 toneladas), barras de acero, cables de cadena, clavos de hierro, cobre, hierro, latón, lunas y espejos, maderas, oro y plata en alhajas, hilaza, tejidos, tierra para loza, vidrios...Además de productos alimenticios y otros. El comercio, pues, "hace introducir las primeras materias para la elaboración, de las que se apoderan las artes y las ciencias...y los instrumentos para su aplicación", y también géneros para el consumo de la ciudad y para su distribución en la Península. Con todo, hay una comparación significativa (y eso que no calculamos la inflación de casi medio siglo): el valor total de las exportaciones como media de los años 1843 y 1844 fue de 81 millones de reales, y la importación, 125; cuando en 1792 había sido, respectivamente, 270 y 700 . 

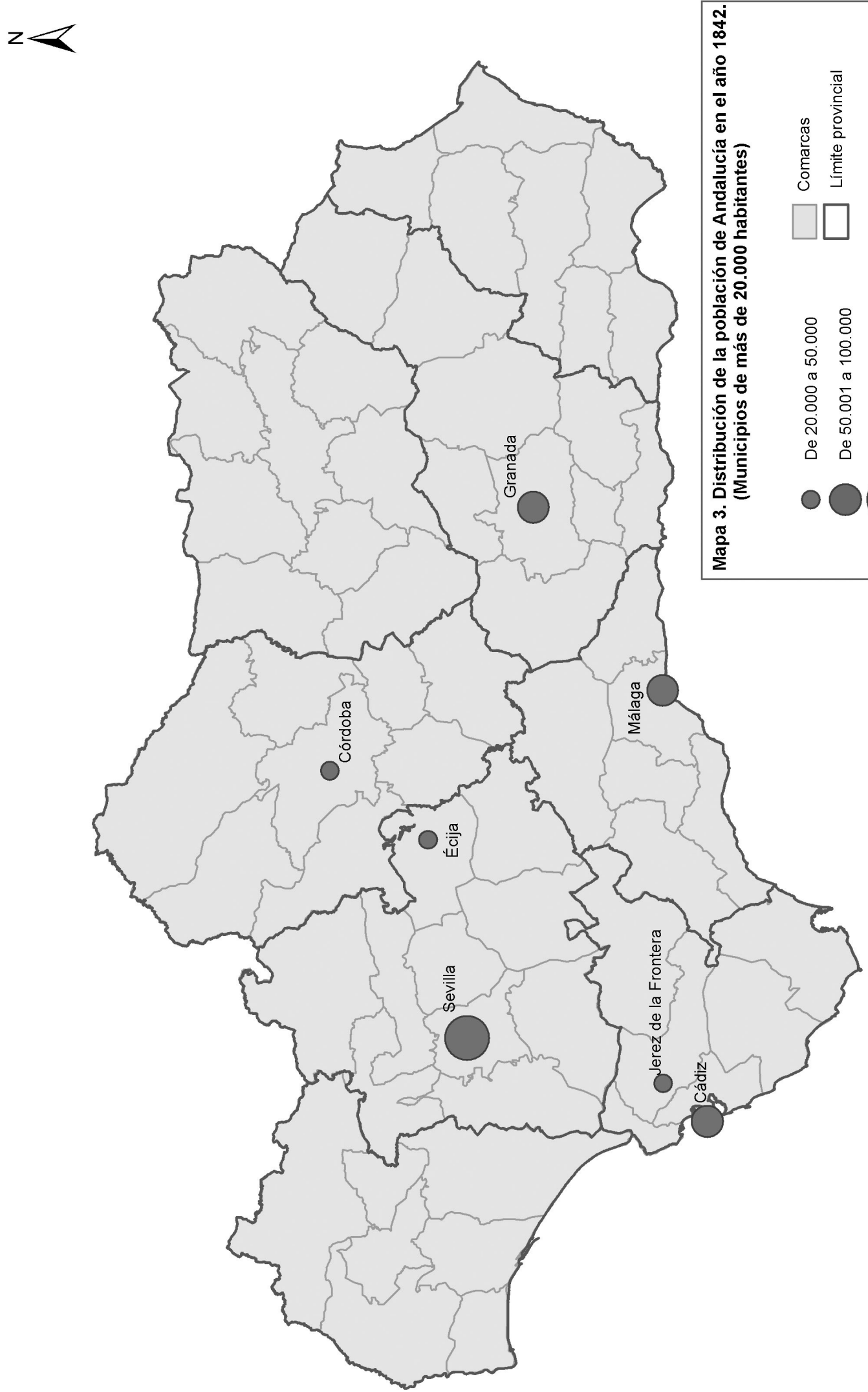


\subsection{Córdoba}

Capital del antiguo reino, provincia en 1833, era ya a mediados del XVIII una ciudad "estancada y decrépita" (LÓPEZ ONTIVEROS, 1990), fundamentalmente agraria, con más de 5.000 jornaleros, pequeño comercio y alguna artesanía. Las noticias del XIX no son mejores; estancamiento demográfico, económico y urbano, según estudia Casas Deza hacia 1860 y lo testifican distintos viajeros, como Borrow, 1842 ("ciudad pobre, sucia y triste") o Ford ("tiene un aspecto verdaderamente oriental, pero por dentro toda ella es decadencia"). Aunque conviene apelar a una fuente menos subjetiva y de cuantificación, que para mediados del XIX es el Diccionario de Madoz, que registra una población de 41.976 habitantes en una ciudad que no había superado el recinto murado andalusí.

Y el agro cordobés de esa fecha no difiere mucho del de un siglo antes, si bien se registran casi 13.000 fanegas más, si es que eran la misma medida. Hay tres cuartas partes de secano (del que el $90 \%$ es labor al tercio, el $5 \%$ de olivar y escasas vides) y apenas 700 fanegas de riego; con casi el $23 \%$ del término de dehesas, arbolado (encinas, alcornoque, pinos castaños), chaparral, matorral y pastos. Así que las producciones eran de trigo, cebada, leguminosas, frutas, hortalizas, ganadería y sus famosos caballos; las artes e industrias se hallaban "muy decaídas", frente al florecimiento de otros tiempos en que se exportaban "para la América y el estrangero"; y el comercio exterior se basaba en aceitunas adobadas para Madrid y alguna obra de platería.

\subsection{Jerez}

Era ya una ciudad muy dependiente de la actividad vinatera en un extenso término municipal y cerca de los puertos de la Bahía. Desde principios del XIX el crecimiento bodeguero continúa: 250 almacenistas en 1811, 513 bodegas en 1837, e incorporación de nuevos empresarios, como Domecq (desde Francia, 1820). Aporta este siglo innovaciones técnicas y, sobre todo, rapidez en el transporte (instalación de ferrocarril y avances de navegación), que posibilitan una exportación más fermentada y no de mosto. Pero también desde mediados de la centuria entra el oidium francés y la filoxera desde Málaga, perdiéndose plantones que son sustituidos por pies americanos injertados de especies propias. 
Pero la caída del comercio con América y el aumento de producción bajaron tanto los precios, "que apenas compensa los trabajos del productor" y sólo el sacrificio "de los industriosos jerezanos puede sostener un lánguido movimiento". La media anual de exportación de vino entre 1837 y 1846 fue de 480.000 arrobas, generalmente por arriería y el puerto fluvial del Portal en el Guadalete hasta el Puerto de Santa María y Cádiz, y los destinos, aparte de alguno al interior de la península, eran Inglaterra, América y Rusia, principalmente. Por lo demás, "fuera de las industrias que son comunes a cualquier población medianamente importante", derivaban de cereales y vinos (espartería, aperos, carretería, construcción de botas y alambiques para destilación de aguardiente) y poco quedaba de la elaboración textil, que fue importante en los siglos XIV y XV.

\section{8. Écija}

La séptima ciudad andaluza con más de 20.000 habitantes en 1842 se sitúa en medio de la campiña, bien comunicada, entre Córdoba y Sevilla, con abundancia de agua del Genil y ya fue capital de un convento jurídico de la Bética. Su eminente posición en el sistema urbano de mediados del XIX va decayendo con el tiempo, por diversas competencias (capitalidades, aglomeraciones metropolitanas, costa...), pero entonces el Diccionario de Madoz la dibuja como una agrociudad, cabecera comarcal, donde predominaba el trigo (unas 350.000 fanegas) y el aceite (400.000 arrobas), "no siendo tan abundante el vino como en otras épocas; porque en estos últimos años se han sustituido a muchos plantíos de viñas, otros de olivares". "No en vano es considerada esta ciudad como la más rica e importante de la provincia después de la capital" $y$ en sus abundantes pastos de grandes dehesas se criaban numerosos rebaños, incluidos caballos ("de gallarda planta y bellas formas") y excelentes toros de lidia". El comercio se basaba en el trigo y el aceite mediante arrieros de Fuentes de Andalucía, hacia Sevilla y Málaga, sobre todo. Se mantenía la industria textil (telares de seda, paños, sombreros), de aceite y harina. Pero se nota en las cifras una cierta decadencia respecto a las de un siglo antes. 


\section{NÚCLEOS ENTRE 10.000 Y 20.000 HABITANTES}

\subsection{Características generales}

En 1842 había 31 núcleos mayores de 10.000 habitantes (aparte de los siete de cabecera), que, como apuntábamos, podrían ser el equivalente a los superiores de 30.000 de ahora; pero eso habrá que demostrarlo, viendo sus funciones y el papel territorial desempeñado. De esa cifra la mayoría (23) contaba con menos de 15.000, y sólo 8 pasaban de ese límite: Puerto de Santa María (cerca de 18.000), Almería, Jaén, Antequera (17.000), Sanlúcar de Barrameda, Lucena (16.600), Osuna y Carmona (15.121). Y cerca estaban Loja y Vélez Málaga (14.396). Así aparecen dos capitales de provincia más, quedando sólo Huelva por debajo de los 10.000; dos núcleos próximos a Cádiz, desarrollados principalmente en el XVIII durante el comercio con América; el mantenimiento de Antequera, con pérdida de peso respecto a 1787; la fortaleza industrial y comercial de Lucena, la importancia agraria de Carmona y, en menor medida, de Loja (en la Depresión Intrabética, entre Granada y Antequera) y Osuna, centro histórico, industrial y cabecera comarcal. Esta última función la ejercen prácticamente todas ellas, añadiéndose la capital de la Axarquía, puerto y exportadora de pasas.

Así, los municipios mayores de 10.000 (mapa 4) difieren de los de 1787, aunque muchos de los que saltan a ese intervalo tenían más de 9.000 a finales del XVIII (Carmona, Utrera o Marchena) o apenas pasan de esos 10.000 a mediados del XIX (Algeciras, Baza, Guadix, Baeza, Martos, Montoro o Aguilar). Algo más (entre 11.000 y 13.000) habían crecido otros, como Vélez Rubio, Huércal Overa, Baena 0 Motril.

Lógicamente, en una economía agraria predominan las agrociudades, especie propia de Andalucía, porque unen la importancia de los productos del campo, generalmente en amplios términos municipales y propiedad concentrada, con industrias derivadas (sobre todo, aceite y harina). La fabricación textil se muestra importante en algunas (Antequera, Baena, Osuna) y otras presentan ciertas especialidades, como lámparas (Lucena), curtidos (Baeza) alfarería (Aguilar) calzado (Guadix). Pero los caminos se citan frecuentemente como malos y obstáculos para el comercio, si bien la arriería era una ocupación relevante, además del tráfico portuario. Existían abundantes tiendas, más ferias de ganado, equipamientos y oficios para 
servir a un área comarcal, y todas ellas eran cabeceras de partido judicial, según la institucionalización de 1834.

\subsection{Las agrociudades del Valle del Guadalquivir}

No es necesario insistir en las favorables condiciones agrarias de este espacio andaluz (tierras allanadas, suelos fértiles, sobre todo los vertisoles o bujeos, y clima mediterráneo algo continentalizado hacia el este), de manera que predomina la clásica trilogía de cultivos (cereales, especialmente trigo, olivos y vides). Obviaremos las repeticiones en la somera descripción que sigue para destacar lo diferenciador de lo que hemos dicho sobre las ciudades andaluzas con más de $10.000 \mathrm{~h}$. (agricultura, ganadería, industria, comercio...). Así, en Úbeda (más de 13.000 habitantes), para empezar de este a oeste, eran importante las leguminosas y la fabricación de grandes tinajas de hasta 120 arrobas de cabida. En Baeza se cita un activo comercio con exportación de granos a La Mancha, Castilla y Valencia con retorno de bacalao, papel, arroz y aguardiente. También, cuatro fábricas de curtidos con ventas en Málaga, Córdoba y Granada, así como el abastecimiento de algunos productos "a muchos pueblos del radio de la ciudad", remarcando la capitalidad comarcal de estas agrociudades.

Mucho más en Jaén (17.387 h.), capital con bastantes equipamientos, organizaciones y entidades para la época. Situada al pie del Subbético (pero con aprovechamiento campiñés y abundante agua en la Vega), producía de $10.000 \mathrm{a}$ 12.000 arrobas de aceite y otro tanto de vino; además de cereales, leguminosas, variedad de hortalizas (algunas tan poco frecuentes entonces como el brócoli) y frutas. Muchos cerros de alrededor estaban cubiertos de vides y olivos, donde no hacía mucho tiempo predominaban los pastos, y se destaca el ganado de labor, bueyes sobre todo. La industria más importante era la derivada de la agricultura y algunas de paños y lienzos (destacaba la fábrica La Constancia) y se lamenta el autor de este informe de la desaparición de la industria sedera, tan importante en la época árabe, con restos aún a finales del XVIII. Se citan varios caminos y la carretera Madrid-Granada por Bailén, pero el comercio era "insignificante...y comerciantes al por mayor, propiamente hablando, no hay ninguno". Había dos ferias y todos los jueves se celebraba un mercado, principalmente de caballerías.

En la cercana Martos (más de 11.000 h) también la agricultura se había convertido en el pilar de la economía, pues se hicieron "desmontes considerables 
en terrenos del común y particulares reduciéndose a cultivo", y manteniéndose otros poblados de encinas, chaparrales y monte bajo. Esperaban poder acelerar el crecimiento económico de Martos, ya que "en el nuevo plan de carreteras se señala a ésta como una de las poblaciones porque cruzará la que dirija a Granada, y en nuestro concepto serán inmensas las ventajas que reportará esta población si dicho plan se realiza, muy principalmente para la extracción favorable de sus aceites, que hoy sufren repetidos descuentos y bajas por el mal estado de los caminos".

Ya en la provincia de Córdoba, había cuatro núcleos campiñeses, además de la capital, Montilla, Baena, Aguilar y montoso, entre los 13.200 del primero y los 10.700 del último, significándose de los rasgos generales la "exquisita calidad" de los vinos de Montilla (con más de 40.000 arrobas de producción, que se exportaba a la provincia y la capital, habiendo comenzado algunos pedidos para Inglaterra) y 46 telares de lino. En Baena tenían fama las telas y bordados, así como la cría caballar; en Aguilar destacan la "tierra blanca y pegajosa que sirve para la fabricación de tejas, ladrillos, cántaros y otras vasijas". Y Montoro participa de la Sierra (colmenas, ganado..) y la Campiña, produciéndose en sus olivares hasta 380.000 arrobas anuales, exportado en gran cantidad. Curiosamente, "casi todas las haciendas tienen interpolados los olivos con higueras, que producen higos de exquisito gusto".

En la circunscripción de Sevilla, además de la capital y Écija, ya consideradas antes, había tres núcleos campiñeses, sobresaliendo Carmona con más de 15.000 habitantes y un amplio término, cultivado casi en su totalidad y con una fuerte concentración de la propiedad. Entre las producciones sobresale el aceite, cuyos sobrantes se exportan a los mercados de Cádiz, y mayormente a Sevilla con numerosa arriería, siendo significativos la denominación de carriles del Aguardiente y de la Lana. También en Marchena, "los sobrantes de los productos del suelo se exportan a Sevilla y pueblos comarcanos por los arrieros de la villa". En Utrera, 13.000 (de campiña alta y baja con dehesas y pastos en las zonas inundables del Guadalquivir, donde destacan la cría de caballos, muy estimados en muchas ferias), hay una infrecuente relación de la matrícula industrial y comercial de 1847, donde se relatan actividades y oficios que, sin duda, señalan una capitalidad comarcal. Por ejemplo, 4 médicos, 2 cirujanos, 3 matronas, 49 tiendas de abacería, 15 zapaterías, 88 albañiles, 10 herreros...Y, como cabecera de partido judicial, juez, notario, 9 procuradores, 6 abogados, escribanos... 
En la provincia de Cádiz, aparte de Jerez de la Frontera, había dos núcleos campiñeses (con menos olivar y vid que en los anteriores) superiores a $10.000 \mathrm{~h}$., Arcos y Medina Sidonia, aunque no son el Valle del Guadalquivir propiamente, sino del Guadalete y Barbate. La primera, 11.300 h., participa también de la Sierra, de donde se extraían maderas para la Marina, siendo esta ciudad caja de reclutas de los pueblos de su partido. Eran famosos los toros y caballos, y tenía bastantes fábricas de curtidos muy apreciados. Medina Sidonia, poco más de 10.000 h., ejercía sobre todo de centro comercial por medio de la arriería, tercera actividad en importancia, tras la agrícola y pecuaria.

\subsection{Núcleos del Subbético}

El Subbético es la parte externa de las sierras béticas, lindante con el Valle del Guadalquivir, suponiendo un importante eje urbano andaluz, porque las surgencias y fuentes kársticas de sus montañas calizas han posibilitado pueblos y ciudades, con áreas de campiña, vegas, localización defensiva de montaña, pasos entre el Valle y la Depresión Intrabética, y una historia de varios siglos de frontera entre la Andalucía del Guadalquivir, conquistada antes por Castilla, y el reino musulmán granadino, que pervive hasta finales del XV.

Y precisamente entre la Vega de Granada y las campiñas de Martos y Baena se halla Alcalá la Real con 11.500 habitantes a mediados del XIX, siendo la agraria la principal actividad con exportación de trigo a Granada, Málaga y su costa; incluso, en años secos, a las campiñas de Córdoba y Sevilla. La feria, concedida en 1688, atraía a mercaderes de muchos lugares, y la situación de cruce se plasmaba en la antigua carretera Granada-Córdoba y la de Jaén hacia Madrid, aparte de numerosos caminos de herradura a Montefrío, Iznalloz, Alcaudete y Baena.

El caso de Lucena (casi 17.000 h.) es especial, pues, además de la agricultura (con más de 100.000 arrobas anuales de aceite) y de las fabricaciones normales en estas ciudades del XIX (especialmente alfarería, grandes tinajas y loza, "parecidas a las de Sevilla y Andújar"), destacaba la producción de lámparas. Merece la pena copiar el párrafo de Madoz, relativo a la belonería, de las que "se cuentan muchas fábricas, en las cuales se trabaja el metal con mucho gusto, para el surtido no solo de España, Portugal y algunos pueblos de Francia... sino también para la Argelia y la Habana. Por excitación de la Sociedad Laboriosa de Lucena, se han hecho ensayos 
de ligas de varios metales, que han dado por resultado sacar piezas tan hermosas, que se confunden con las de plata; contribuyendo además estas operaciones, a que los artistas adquieran algunos conocimientos de metalurgia". Esto es, iniciativas, instituciones, arte, nuevas tecnologías, importantes mercados...La industria actual tiene sus precedentes. En Priego se menciona el pasado auge de la seda, de origen morisco, aun importante en el XVIII: "En otro tiempo fue muy opulenta esta villa con las fábricas de sedería, pues se empleaban en ella en tafetanes, cintas y pañuelos más de 60.000 libras de seda; pero en la actualidad solo existen 2 tornos en que se tuerce la poca seda que produce la cría de gusanos".

En Osuna (más de 15.000), además de la importancia olivarera, como en todo el Subbético, sobresale una considerable industria textil, "que surte a este y pueblos limítrofes", repitiéndose de nuevo el carácter de centro comarcal, reforzado en este caso por la existencia de una Universidad desde 1548. En Morón destacaba la exportación de lana y se repara en la dejadez de los caminos, recomendándose en el Diccionario la apertura de una carretera desde Ronda a la general de Andalucía por Utrera. Y precisamente Ronda, con casi 14.000 habitantes, era otra ciudad relevante, en el límite de la zona penibética y no propiamente en el Subbético, con una cuenca sedimentaria extensa y de buenas producciones agrarias, "entre las que sobresalen los exquisitos peros de Ronda, conocidos y apreciados en todo el reino ". Y, una vez más, "las artes e industria podían aumentarse y perfeccionarse si estuvieran abiertos los caminos de comunicación con la capitales de Andalucia", aunque se exportaban cordobanes y botines. De nuevo, también, la constatación de comercio, profesiones y actividades propias de una cabecera comarcal.

\subsection{La Depresión Intrabética}

Se trata de un surco geológico entre las unidades béticas mencionadas (Subbético y Penibético), rellenado de sedimentos procedentes de la erosión de ambas laderas, componiendo un espacio agrario de secano en clima continentalmediterráneo con importantes y antiguas vegas (Baza, Guadix, Granada...). Es un eje de comunicación natural (con alguna interrupción, como la Sierra de Huétor y el puerto de la Mora) recorrido desde antiguo por calzadas y caminos (hoy autovía autonómica del 92), en cuyo borde han surgido y desarrollado ciudades, que forman uno de los sistemas urbanos más estables de Andalucía. Concretamente a mediados del XIX pasan de los 10.000 habitantes, además de Granada, cinco ciudades desde Vélez Rubio, al nordeste del eje, hasta Antequera, enlace con el Valle del Guadalquivir. 
Y precisamente la primera (11.300 h. en 1842 y apenas 7.000 en 2005; aunque entonces incluía Chirivel y Taberna, 1.800 y 1.081, ahora) ostenta una clara función agraria, algo de industria, comercio y, sobre todo, viaria, pues "además de los caminos locales que conducen a los pueblos comarcanos, cruza la población y su término de E. a O. la carretera de Cataluña, Aragón y Valencia para Granada y demás puntos de Andalucía". También a orillas de la calzada romana estaban las históricas Baza y Guadix, con algo más de 10.000 habitantes y amplios términos municipales, cabeceras comarcales (la primera se introducía por el Valle del Almanzora), agricultura de secano y sendas vegas, industrias (en Guadix tenía cierta importancia la del calzado), servicios, profesiones y oficios de cabecera comarcal, con un buen comercio, ferias anuales (" concurridísima", "en la que se venden muchos géneros y ganados") y mercado semanal. Al oeste de la vega de Granada y suficientemente distanciada (como en las otras dos ciudades citadas) de ella (unos $60 \mathrm{~km}$ ) para organizar su espacio comarcal, se halla Loja, con casi 15.000 habitantes y características similares a Baza y Guadix, repitiéndose las quejas de los malos caminos que impedían un mayor peso industrial aprovechando la relativa cercanía del puerto de Málaga.

Antequera contaba con 17.031 habitantes (los mismos que tenía Almería, por ejemplo) y la agricultura como principal actividad económica, desarrollada sobre 100.000 fanegas de tierra, el $30 \%$ regadas, cuyos excedentes se vendían en Málaga y otros lugares. Existían dos dehesas, denominadas significativamente de Yeguas y de Potros, con animales dedicados al trabajo agrario y el transporte. La industria era importante, con trece fábricas de hilados y tejidos de lana, y un gran número de telares, siendo famosas las bayetas, que se exportaban a otros lugares del reino y al extranjero. Había también diez fábricas de curtidos, otras tantas alfarerías, cinco de sombreros, más batanes, fábricas de almidón, tintes, grabadoras de ropa, molinos de pan, fábricas de fideos, cera, papel, cañamazo... y hasta de chocolate.

A esta amplia y variada industria, que para la época constituía una abultada producción y ocupaba buena parte de la población, se unía un numeroso comercio con 35 tiendas, "surtidas en su mayor parte de todos los géneros de telas, sederías y quincalla", y 74 abacerías, lo que indica claramente una ciudad floreciente con alto nivel de vida y un centro comarcal al que iban a aprovisionarse desde los pueblos del entorno. Esto se refuerza con una serie de artesanos y profesiones liberales de todo tipo (carpinteros, zapateros, plateros, agrimensores, herreros, confiteros...) y la existencia de dos cafés. 


\subsection{La Costa}

La comparación de los mapas urbanos 1842 y 2005, señalan dos grandes diferencias: el crecimiento de las áreas metropolitanas y del litoral. En efecto, el esquema costero en 1842 no se distingue de la pauta general de entonces: dos ciudades grandes (Málaga y Cádiz), equivalentes a las dos capitales históricas del interior (Sevilla y Granada) a suficiente distancia para la organización espacial; menos evidente en la costa, donde la actividad portuaria y sus consecuencias añaden un plus considerable a la función urbana de servicios. A esos dos centros se suman cinco mayores de 10.000 habitantes, que, descontado el entorno de Cádiz, se quedan en tres desde Almería a Algeciras, indicando una menor densidad de centros comarcales que en las otras tres unidades analizadas (Valle, Subbético, Intrabética) y ausencia, también, de un centro mayor de 10.000 entre Málaga y Algeciras. Nada que ver, pues, con las conurbaciones actuales de la Costa del Sol y de gran parte de nuestro litoral, en el que, además de la metropolización mencionada, cuenta el turismo y la agricultura intensiva, inexistentes en el XIX. Aun así vamos a ver una agricultura tropical y cierta actividad portuaria, aparte cultivos mediterráneos e industrias.

Próximo a Cádiz, El Puerto de Santa María había experimentado un auge en el XVIII en relación con el comercio americano y, según IGLESIAS, a mediados de éste (Catastro de Ensenada) las rentas más cuantiosas procedían de la industria y el comercio (la tercera del Reino de Sevilla, tras la capital y Cádiz). Y, como compensación a la crisis portuaria, a partir de la segunda mitad del XVIII tienen lugar una serie de iniciativas industriales, como ocurrió en otras ciudades andaluzas (Cádiz, por ejemplo), sobre todo las textiles. Pero la regresión continúa, pues en 1842 había 17.930 habitantes (20.000 hacia 1750), y la agricultura había cambiado algo en un siglo, predominando el cereal secano y retrocediendo el olivar ("por no poder competir con los de Morón y Sevilla", según el Diccionario de Madoz, de hacia 1845). En cambio, se denota una elaboración de caldos (sobre todo, "excelentes vinos blancos muy apreciados de los extranjeros") y licores "para exportarlos a diferentes puntos de dentro y fuera de la Península, ocupando un regular número de operarios, en cuyas bodegas casi no cesa en todo el año el trabajo". El comercio también estaba relacionado con esa actividad, de manera que se importaban maderas y hierros para toneles, más aguardientes y vinos de Jerez. En el bienio 1844-45 entraron en el puerto 102.000 arrobas de vino y 10.000 de aguardiente, y salieron 926.382 (el $98 \%$ al extranjero) y 3.500 , respectivamente. 
Cerca, Sanlúcar de Barrameda (17.000 h.) tenía un tráfico portuario escaso con el extranjero (unas 4.000 arrobas de vino exportadas en 1845, y 50.000 unidades de naranjas y limones, como géneros más destacados) con una entrada y salida de buques similar a la del Puerto en torno a los 350 de media anual. Y, también como en aquella ciudad, destacaba la producción de vinos, vinagres y aguardientes, especialmente la manzanilla, obtenida de las tierras albarizas. Se cita además la producción de toda clase de hortalizas, melones, sandías y patatas en los navazos 0 arenales.

Hacia el este se halla Algeciras con 11.000 habitantes y una actividad marítima considerable: posesión de bandera mercante propia, de color amarillo y azul, y 661 marineros útiles, embarcaciones de todas clases. En 1844 hubo un registro de 69 buques entrados desde el extranjero, con un total de 3.625 toneladas y 532 tripulantes; y la importancia de Gibraltar la revelan las cifras anuales de cabotaje, con 3.700 .000 reales en importación y 5.600 .000 en exportación, frente a 48.000 en total con el extranjero. Un dato significativo, quizás relacionado con el Peñón: en esa valoración se incluyen más de dos millones de reales en dinero efectivo exportado.

Por lo demás, la agricultura era poco importante en un término montuoso y forestal, debiéndose traer de fuera una parte del consumo, y la industria se componía de cuatro fábricas de curtidos y algunas de tejidos. Es importante citar que en esos mediados del XIX se detectaban dos problemas, que aún no se han resuelto totalmente: uno, la necesidad de construir un gran puerto, para aprovechar la inmejorable situación entre dos continentes y dos mares; otro, la apertura y mejora de vías terrestres, sobre cuyas carencias se dice, entre otras cosas: "la carretera de Cádiz por Tarifa, está de tal modo intransitable, que aun las personas que tienen miedo al mar, se embarcan, porque consideran la navegación menos peligrosa, que el exponerse a pasar por breñas y despeñaderos".

Hasta Málaga no hay ninguna población con más de 10.000 habitantes (Estepona 8.000), alcanzando casi 15.000 Vélez Málaga, capital de la Axarquía y con un puerto de poco movimiento (unos 170 buques entrados al año y 150 salidos, el $98.5 \%$ de cabotaje). Se exportaban pasas al extranjero (moscatel y larga; 20.000 arrobas de media 1844-45, habiendo disminuido por los aranceles de fuera), maíz (Valencia y Cataluña), caña dulce, miel, batatas, aceite (sobre todo a Francia), naranjas, limones, higos y otros productos. Pero las embarcaciones más importantes 
tenían lugar en Málaga, previo transporte de arrieros, que también circulaban hacia el interior. La pesca era para consumo local y la industria y el comercio, incluida una feria en septiembre, las propias de un centro comarcal.

Esta costa era el asiento de una agricultura tropical, que llegaba hasta Motril (11.000 h.), principalmente la caña de azúcar, que "se ha conservado sin interrupción desde la época de los moros hasta la presente con el mismo cultivo y sistema de fabricación que aquellos", cuando se extendía por las vegas mediterráneas andaluzas desde Adra a Marbella. Pero en el XIX sólo hasta Vélez Málaga, incluyendo la vega de Motril, ciudad en la que había dos fábricas (una de sangre, sin uso; y otra hidráulica) con una molienda de 80.000 arrobas de caña, dando lugar, por otro lado, a 300 arrobas de ron, de buena calidad, premiado en la exposición de 1828. La decadencia del cultivo se atribuye en el Diccionario de Madoz, sobre todo a la disminución de la población morisca y a la competencia americana.

La producción de algodón se había reducido, sobre todo por la implantación de aranceles desfavorables y, según el Diccionario de Madoz, la competencia de tejidos catalanes dejó la fabricación en una sexta parte, saliendo el algodón para Cataluña "sin más preparación que el despepito. Había algunas pequeña fabricaciones más y 4 hornos reverberos para las menas de plomo de Sierra de Lújar, de fundición temporal. Además de azúcar, algodón y arroz, se cosechaban batatas, habichuelas, limones y naranjas (exportados en gran cantidad, sobre todo la batata, para Valencia, Murcia, Sevilla y Argelia) y otros consumidos en la ciudad o su comarca: vino, aceite, maiz, frutas...Son notables los intentos de innovación agrícola con la introducción de productos como el café, añil y tabaco.

El puerto constituía el acceso natural desde Jaén, pero se veía obstaculizado por los malos caminos, pues incluso el de Granada ("declarado provincial") "se ha dejado destruir a punto de ser molesto hasta para la arriería". Se disponía de 4 buques de 17 a $53 \mathrm{Tm}$ para el cabotaje y 7 barcas para la pesca, que ocupaban a 104 hombres, entre los dos puertos considerados entonces de Motril, Calahonda y Baradero. La ciudad contaba con una feria anual, ocho casas de comercio al mayor y varias tiendas, constituyendo un centro de atracción para su comarca, el Valle de Lecrín y la parte occidental de las Alpujarras. 
Después de Adra (7.400 h.), Almería, capital provincial desde hacía solo nueve años, registraba cerca de 18.000 habitantes y una economía, según el citado Diccionario, no muy próspera. Abundaba el maíz ("en los años en que el río riega diversas veces la vega "), cebada y trigo, "siendo insignificante la de los demás granos y semillas", teniéndose que importar gran parte del abastecimiento del mercado. La industria consistía en nueve molinos harineros, algunas fábricas de ladrillos y de albayalde, "que se benefician por el plomo de Sierra de Gádor ", y fabricación de textiles y cerámicas. La exportación mayor consistía en plomo (a Marsella y otras ciudades francesas), esparto (a Lisboa y otros puerto lusos) y barrilla (a Málaga y Galicia). Las comunicaciones eran malas y "no hay diligencia, ni sillas de posta para ningún punto".

\subsection{Otros}

A unos $20 \mathrm{~km}$ de la costa se situaba Huércal Overa, en el valle del Almanzora, y en el camino hacia Lorca en Murcia, siendo, con Vélez Rubio, el único núcleo provincial con más de 10.000 habitantes (12.336), además de Almería. Era un centro comarcal con bastante comercio y arriería, una feria anual de 17 días, un mercado semanal y producciones de la trilogía mediterránea, leguminosas, hortalizas, frutas y la especificidad de "alguna yerbas medicinales y muchas plantas aromáticas", del matorral xérico mediterráneo. Existían telares de lienzo y colchas y algunos vecinos vivían de las minas de Sierra Almagrera.

\subsection{Comparación 1842-2005}

La anterior enumeración de las ciudades mayores de 10.000, su funcionalidad y papel territorial a mediados del XIX nos facilita la comparación con las superiores a 20.000 de ahora a dos efectos principales: verificar los cambios y comprobar si los límites poblacionales indicados de ambas fechas son equivalentes. 
Cuadro 6. Comparación 1842 (Más de 10.000 h.) y 2005 (Más de 20.000 h.)

\begin{tabular}{|c|c|c|c|}
\hline & 1842 & 1842 y 2005 & 2005 \\
\hline \multirow[t]{8}{*}{ Valle Guadalquivir } & Baeza & Úbeda, Jaén, Martos & Linares, Andújar \\
\hline & Montoro, Aguilar & Córdoba, Baena, Montilla & Puente Genil, Palma Río \\
\hline & Marchena & Écija, Carmona, Sevilla, Utrera & Lebrija \\
\hline & "Medina Sidonia" & "Arcos", Jerez & "Almonte" \\
\hline & & & Alcalá Guadaíra, Dos Hermanas, \\
\hline & & & Los Palacios, Coria, Mairena Alj. \\
\hline & & & S. Juan Azn., Tomares, Camas, \\
\hline & & & La Rinconada \\
\hline \multirow[t]{4}{*}{ Subbético } & & Alcalá la Real & Cabra \\
\hline & & Priego, Lucena & \\
\hline & Osuna & Morón & \\
\hline & & "Ronda" & \\
\hline \multirow[t]{2}{*}{ Depr. Intrabética } & Vélez Rubio & Baza, Guadix, Granada, Loja, & \\
\hline & & Antequera & \\
\hline \multirow[t]{10}{*}{ Costa } & & Huelva & Lepe, Isla Cristina \\
\hline & & Sanlúcar, Cádiz, Puerto Sta Mª & Rota, Puerto Real, San Fernando, \\
\hline & & & Chiclana, Conil, Barbate, \\
\hline & & Algeciras & San Roque, La Línea, Los Barrios \\
\hline & & & Estepona, Marbella, Fuengirola, \\
\hline & & Málaga, Vélez M. & Benalmádena, Mijas, "Alhaurín G" \\
\hline & & & "Alhaurín T", "Coín”, Torremolinos, \\
\hline & & & Rincón V., Nerja, \\
\hline & & Motril & Almuñécar, \\
\hline & "Huércal Overa" & Almería & Adra, Ejido, Roquetas, Vícar, Nijar \\
\hline
\end{tabular}

Nota: Entre comillas, las poblaciones incluidas en la grandes regiones andaluzas aunque no pertenezcan totalmente a ellas, a efectos de clasificación. Quizás se podrían haber incluido en otro apartado, especialmente Coín o Huércal Overa (en este caso, así lo hemos hecho en el texto), lejos de la costa, o Medina Sidonia, Arcos o Almonte, periféricas al Valle del Guadalquivir.

Del cuadro anterior pueden extraerse algunas conclusiones. La primera es la coincidencia existente en dos ejes urbanos andaluces importantes, el Subbético (salvo el caso de Cabra) y la Depresión Intrabética, de ciudades mayores de 20.000 
en el 2005 y de 10.000 en 1842. Esto, en principio, avala la tesis de la equivalencia de ambos límites, y, por otra parte, viene a señalar la estabilidad urbana de esas dos áreas, que presentan una sucesión de centros comarcales, siguiendo en el primer caso el contacto sierras subbéticas-campiñas, y, en el segundo, la antigua calzada bética, hoy autovía del 92 . Y algo importante, la distancia de esos centros es mayor en la Depresión de peores condiciones territoriales (clima algo continentalizado, aridez y suelos no siempre buenos). Sólo hay una excepción en cada región, que tenían más de 10.000 habitantes en 1842 y no llegan a 20.000 en el 2005, a diferencia de las otras 10 coincidencias: Osuna y Velez Rubio. La primera contaba con $17.345 \mathrm{~h}$. en el 2005 y 17.594 un año después; es decir que se acerca al límite y, desde luego, se trata de una cabecera comarcal, junto con Estepa (12.000 h.). Más difícil es el caso de Vélez Rubio, con solo $6.905 \mathrm{~h}$. en 2005 (aun sumando los dos municipios segregados poco después de 1842 , con casi 3.000 hoy) revelándose una considerable pérdida (el máximo lo alcanzó en 1940 con 10.779), aunque sigue siendo la cabecera de la comarca de los Vélez.

En cambio, el Valle del Guadalquivir tiene 15 núcleos con más de 20.000 en el 2005; que en 1842 tenían menos de 10.000 (y algunos hasta menos del millar de habitantes) y sólo 12 en que coinciden ambos límites. Y en la costa hay 9 comunes y 28 en 2005; pero también cuentan 5 con más de 10.000 en 1842 y no llegan a 20.000 en el 2005. Una primera conclusión es que en el Valle han perdido importancia más núcleos que en la costa (ninguno, realmente, porque Huércal Overa está ahí para no abrir un apartado de un solo elemento de la clasificación), donde lo que ha habido es gran crecimiento de los centros del XIX y numerosa aparición de otros. Y, como dijimos, las cabeceras comarcales litorales están a mayor distancia que en el Subbético y la Depresión Intrabética. También en el Valle hay espaciamiento, salvo quizás en algunos en los que hoy existe cierta bicefalia comarcal (Úbeda-Baeza, Montilla-Aguilar, Marchena-Morón), además de Jaén-Martos. 


\begin{tabular}{|l|c|c|c|}
\hline \multicolumn{7}{|c|}{ Cuadro 7. Población en $\mathbf{1 8 4 2}$} & $\mathbf{y}$ 2005 & de cinco agrociudades & \\
\hline & 1842 & 2005 & $\% 1842-2005$ \\
\hline Baeza & 10.851 & 16.056 & 48.0 \\
\hline Montoro & 10.732 & 9.690 & -9.7 \\
\hline Aguilar & 11.836 & 13.657 & 15.4 \\
\hline Marchena & 11.620 & 19.089 & 64.3 \\
\hline Medina Sidonia & 10.534 & 10.802 & 2.5 \\
\hline TOTAL & 55.573 & 69.294 & 24.7 \\
\hline
\end{tabular}

Pero volvamos al análisis de las diferencias entre 1842 y 2005 en los límites 10.000-20.000 habitantes, respectivamente. La pérdida de importancia de algunas agrociudades se demuestra en el cuadro 7 y se explica precisamente por la menor incidencia económica de la agricultura y la competencia espacial, notándose un mayor crecimiento en Marchena, un tanto alejado de Morón y en medio de la campiña sevillana, y decrecimiento en Montoro, no muy lejos de la ciudad califal. Por lo que atañe a los nuevos núcleos mayores en el 2005, es necesario establecer tres situaciones diferentes en el Valle:

a) Las ciudades que en 1842 se acercaban a los 10.000, como Cabra (9.576 h.), cuya importancia industrial veremos más adelante, y Andújar (9.353), que pueden considerarse en el espacio común 1842-2005

b) Los núcleos aislados que han ganado población y funciones entre 1842 y 2005: Linares, por la minería desde la segunda mitad del XIX y la industria posterior, sobre todo automovilística; Puente Genil, Palma del Río, Lebrija y Almonte, por expansión de nuevos regadíos e industrias agroalimentarias, registrando ahora más de 20.000 h., cuando en 1842 oscilaban entre los 6.408 de Puente Genil y los 3.779 de Almonte.

c) Municipios del área metropolitana de Sevilla, que han crecido recientemente y de forma espectacular (cuadro 8) por el efecto, común por lo demás, de aumento demográfico en las periferias de las grandes ciudades. 


\begin{tabular}{|l|c|c|c|}
\hline $\begin{array}{l}\text { Cuadro 8. Población en } 1842 \\
\text { Metropolitana }\end{array}$ & 2005 en municipios del Area \\
\hline & 1842 & 2005 & $\% 1842-2005$ \\
\hline Alcalá de Guadaíra & 6.702 & 64.990 & 870.0 \\
\hline Dos Hermanas & 3.498 & 114.672 & 3.177 .1 \\
\hline Los Palacios y Villafranca & 3.787 & 35.222 & 826.3 \\
\hline Coria & 3.184 & 26.499 & 733.3 \\
\hline S. Juan de Aznalfarache & & 20.121 & \\
\hline Tomares & $699^{*}$ & 20.705 & 5.732 .9 \\
\hline Mairena del Aljarafe & 640 & 39.065 & 6.003 .1 \\
\hline Camas & 662 & 27.706 & 4.096 .7 \\
\hline La Rinconada & 389 & 33.370 & 8.478 .4 \\
\hline TOTAL & 19.561 & 382.350 & 1.854 .7 \\
\hline
\end{tabular}

* En 1842 Tomares S. Juan de Aznalfarache formaban un solo municipio con 699 habitantes.

Huércal Overa (12.300 en 1842, 16.170 en 2005) responde a una subida hasta principios del XX (más de 17.000 en 1910) por efecto de las repercusiones mineras; con disminución después, recuperación hasta 1960 y emigración posterior (1970, 11.600 h.) como en tantos otros núcleos andaluces, y subida hasta ahora. Aparte de este pueblo, que no es litoral, en la costa también hay que establecer una clasificación de los mayores de 20.000 en el 2005 :

a) Las ciudades que en 1842 se acercaban a los 10.000, San Fernando (9.792 h., aunque después la trataremos con cierta extensión) y Chiclana (9.144), que pueden considerarse en el espacio común 1842-2005.

b) Los núcleos más o menos aislados y con actividad portuaria que han ganado población y funciones (agricultura, turismo, servicios...) entre 1842 y 2005, pudiéndose distinguir dos tipos:

a. Los que forman cabecera comarcal: Lepe en la costa Noroeste de Huelva y, en menor medida, Isla Cristina; Barbate en la Janda y Conil como centro secundario; Adra, como núcleo histórico del Poniente almeriense; y en el Valle del Guadalhorce, Coín y los dos Alhaurín, aunque evidentemente no son puertos. Queda el caso de Nerja, más difícil de catalogar, como núcleo secundario de la Axarquía litoral; y Almuñécar, de igual función respecto a Motril. 
b. Los que se desarrollan en el área de influencia de otras grandes ciudades, como la Bahía de Cádiz (Rota y Puerto Real) o la de Algeciras (San Roque, La Línea y Los Barrios).

c) Los municipios de la Costa del Sol desde Estepona a Rincón de la Victoria, que han crecido recientemente y de manera espectacular (cuadro 9) como consecuencia del turismo. No es necesario advertir que en toda clasificación existen solapamientos, de tal manera que muchos de ellos, sobre todo Marbella, centran un área comarcal y también son puertos, aunque predominantemente deportivos. Y que, por ejemplo, en Lepe tienen también repercusiones las urbanizaciones de playa.

d) Los núcleos que, aun teniendo turismo y otras funciones (servicios, comercio...), responden más a la agricultura forzada del Poniente almeriense y sus proximidades: Ejido, Roquetas, Vícar y Níjar, aunque en este último caso conviene advertir que, si bien en el 2005 pasaba efectivamente de los 20.000, cuenta con un núcleo histórico de unos $3.000 \mathrm{~h}$. y varias entidades.

\begin{tabular}{l|c|c|c|c|}
\hline \multicolumn{2}{|c|}{ Cuadro 9. Población en $\mathbf{1 8 4 2} \boldsymbol{y} \mathbf{2 0 0 5}$ en municipios de la Costa del Sol $\boldsymbol{y}$ el Poniente almeriense } \\
\hline & 1842 & 2005 & $\% 1842-2005$ \\
\hline Estepona & 8.088 & 58.603 & 624.4 \\
\hline Marbella & 5.105 & 125.519 & 2.358 .7 \\
\hline Fuengirola & 1.182 & 63.899 & 3.484 .4 \\
\hline Benalmádena & 1.080 & 50.298 & 4.557 .2 \\
\hline Mijas & 4.033 & 61.147 & 1.416 .2 \\
\hline Torremolinos & 785 & 58.683 & 7.375 .5 \\
\hline Rincón de la Victoria* & & 33.817 & \\
\hline El Ejido** & & 75.969 & \\
\hline Roquetas de Mar & 2.200 & 71.740 & 3.160 .9 \\
\hline Vícar & 1.100 & 20.220 & 1.738 .2 \\
\hline Nijar & 5.090 & 26.070 & 412.2 \\
\hline $\begin{array}{l}\text { TOTAL } \\
\text { * No era municipio en 1842. } \\
\text { ** Pertenecía a Dalías. }\end{array}$ *** Sin Rincón de la Victoria y El Ejido. Con ambos, 645.965 habitantes y un crecimiento del conjunto del $2.154 \%$ \\
\hline
\end{tabular}




\section{PUEBLOS ENTRE 6.000 Y 10.000 HABITANTES}

En 1842 había 41 núcleos entre 6.000 (redondeo de 5.865, que sería el límite, según la población total de Andalucía en 1842) y 10.000 habitantes, y, como dijimos, el límite primero sería el equivalente a los 20.000 de 2005, teniendo en cuenta la población total de Andalucía. Vamos a analizar si eso es así (tal y como hemos visto que puede ser válido para los de 10.000), utilizando, así mismo, algunos criterios más que el puramente demográfico; principalmente, funciones, distancia a otros centros y situación actual.

En Almería pasan algunos a la categoría superior a 6.000, sea por aumento de los secanos (Los Vélez) o de los regadíos del Almanzora (Albox y Cuevas), así como el puerto de Adra, donde podemos iniciar un recorrido litoral o próximo a él (Albuñol), que va rellenando la costa de pequeños puertos pesqueros, como Estepona. Si bien, por el contrario, Ayamonte baja de población desde 1787; de manera que Huelva sólo cuenta con la capital. El resto se refiere a expansiones agrarias (llanos de Don Fadrique o Íllora en el Subbético de Granada; Alcalá de los Gazules; valle del Guadalhorce, Álora. Es notable el poblamiento serrano al norte de Sevilla (Constantina y Cazalla), Cádiz (Ubrique y Olvera) e incluso las Estancias almerienses (Oria) y es de reseñar Alcalá de Guadaíra (primer núcleo emergente en la actual área capitalina), agrario y aprovisionador de pan a Sevilla.

\subsection{El Valle del Guadalquivir}

Linares tiene la mayor parte del término en Sierra Morena, de donde se extraía el mineral, principal factor de su desarrollo, habiendo constancia de arrendamientos desde 1706, y se sabe que hacia 1740 se producían unas 12.000 arrobas de plomo y 20.000 de alcohol (polvo para fundición y pintura). Pero a mediados del XIX la actividad había decaído, contando 6.567 habitantes en 1842, si bien Madoz cita una casa donde se fabrica la munición; $y$, además de las minas, existía una agricultura de secano con buenas producciones de trigo, cebada y aceite (16 molinos), más algunas huertas. Se menciona ganadería de todo tipo en la Sierra (poblada de encinas, lentiscos, coscojas y jaras) y varias dehesas con un total superior a 5.000 fanegas. No obstante, las nuevas poblaciones de mediados del XVIII (La Carolina, Guarromán, etc.) se hacen con términos municipales a costa del de Linares, que sufrió un fuerte quebranto en su agricultura. Y fue el auge minero de la segunda mitad del XIX el que 
da lugar a un crecimiento demográfico espectacular, alcanzando 31.151 habitantes en 1877. En 1842 era cabecera de partido judicial y a suficiente distancia, para la época, de Úbeda y Baeza como para considerarla centro de una comarca con las mencionadas nuevas poblaciones.

Estas dos últimas circunstancias aparecen también en Andújar, donde en el Diccionario de Madoz se alude a canteras de mármol y fabricación de tejas, ladrillos, loza y "las famosas alcarrazas y otras vasijas de barro poroso muy delgado, de color blanquecino que se exportan a Madrid y otros muchos puntos por ser muy a propósito para enfriar el agua". Pero, sobre todo, es que en 1842 tenía 9.353 habitantes, con lo que podemos considerar a ambas una función territorial similar a los núcleos de 20.000 actuales. Más dudoso es el caso de los pueblos campiñeses de Córdoba: Bujalance, Castro del Río, La Rambla y Puente Genil, aunque eran capitales de partido judicial, salvo el último, que precisamente es el único que ahora pasa de los 20.000 (debido a un desarrollo industrial de finales del XIX), pero en 1842 la mayor parte de lo cultivado se dedicaba a olivar, generando exportación y varios molinos de aceite, mientras el cereal era escaso y se importaba. A orillas del Genil había muchas huertas, aunque podían producir más si no fuera "por los crecidos costos que tienen las anorias y grúas con que se riegan".

La Rambla está demasiado cerca de Montilla y, quizás, Castro, mientras que Bujalance se halla entre aquél y Montoro. No obstante, los caminos se describen como muy malos y "en ciertas épocas del año es imposible dar salida a los granos y aceites" de Bujalance, siendo en todos ellos la agricultura la principal actividad, aunque también había alguna producción textil (bastante seda en Castro) y alfarera, así como ferias anuales. La población era importante, en torno a los 9.000 habitantes, salvo Puente Genil, que pasaba poco de los 6.000 .

En la campiña sevillana, El Arahal, 6.988 h. (queda cerca de Marchena, más importante y cabeza judicial) era un núcleo agrario que exportaba los sobrantes, sobre todo aceite, a la capital. En cuanto a Alcalá de Guadaíra (6.702 en 1842), su desarrollo es reciente como ciudad dormitorio e industrial del Área metropolitana capitalina. Lebrija sí que era capital judicial y estaba suficientemente alejada de Sevilla y Utrera como para concederle una importante función territorial. Contaba 6.271 habitantes (aunque se apuntan más de 8.000 en otras fuentes), disponía de ciertos establecimientos, y servicios, sobre todo una cátedra de Humanidades ("para 
perpetuar la memoria del ilustre y sabio Antonio de Nebrija") y se trabajaba en algunos talleres y fábricas: lana, alfarerías además de 40 lagares y 23 molinos de aceite. Y es que, como sabemos, la principal producción en el agro andaluz era la trilogía mediterránea (cereal y legumbres, aceite y vino); en este caso con exportaciones hacia los puertos de Cádiz.

\subsection{El Subbético}

Constituye, como dijimos, un eje urbano importante en Andalucía; y por eso, aparecen nueve núcleos entre 6.000 y 10.000 habitantes, tantos como en el Valle del Guadalquivir. Son también fundamentalmente agrarios, aunque hay algunas especificidades (seis son cabeceras judiciales), diferentes pesos demográficos y distancias variables. Cazorla (en los límites con el Prebético) está suficientemente apartada como para ejercer de cabecera comarcal, incluso más que ahora, que sólo añade 700 habitantes a los de 1842 (7.383). Además de la agricultura y su fabricación derivada, contaba con abundantes maderas en la sierra (sobre todo, encinas y pinos carrascos y salgareños) "para la construcción civil y náutica". Alcaudete, en cambio, no era capital judicial (6.242 h) y está próxima a Alcalá la Real, aunque se cita en el Madoz una cierta actividad comercial con Jaén, Granada, Málaga, Córdoba y Priego.

En los Montes de Granada había en 1842 dos núcleos con más de 6.000 h., de producciones agrarias y demasiado próximos para considerarlos centros comarcales, especialmente íllora (6.359 h), mientras que Montefrío alcanzaba casi los 8.000 y era cabecera de partido judicial. Y lo mismo cabría decir de Rute (7.640 h) y Cabra, ya en Córdoba, demasiado próximos a la importante Lucena, aunque eran cabeceras judiciales.

Sin embargo, merece la pena pararse en el caso de Cabra (9.576), que tenía a mediados del XIX una notable actividad industrial, tanto que la agricultura "escasea de brazos suficientes para llevarla a más alto grado de perfección, con motivo de que es muy numerosa la clase de artesanos que se dedican a todos los oficios y artes mecánicas propias de una gran población". La relación es larga: fabricación de cobre, cera, faroles, curtidos y paños; 15 telares; nueve molinos harineros; otras tantas fábricas de chocolate; 70 molinos de aceite (23 con prensa, destacando el del 
conde de Altamira con una prensa hidráulica de gran potencia), y una serie de talleres menores (carpintería, jabón, cerrajería, calderería, alfarerías, alambiques...), más tiendas de todo tipo.

Y "el comercio más principal y directo puede decirse que se hace con la plaza de Málaga. Se extrae la mayor parte de aceite para la anterior población, alguno para Castilla y aun para Granada y Valencia, cuando son cortas las cosechas de Levante; vino y vinagre para Córdoba y su campiña, aguardiente para Écija, Bujalance y provincia de Jaén; frutas y hortalizas para Lucena, Córdoba, parte de su provincia y de la de Sevilla; patatas para la de Málaga; silla finas y bastas, puertas ventanas y toda clase de madera labrada para la provincia y pueblos inmediatos; útiles de labor, piezas de carreta, etc., para Écija y otros puntos; piedras de molino para La Carlota y pueblos de las inmediaciones de Cabra; zumaque (producto de un arbusto, utilizado como curtiente por su abundante tanino) a varios puntos, y jaspes y mármoles para Sevilla, algunos pueblos de la provincia de Jaén, Málaga y otras partes. Hay ocho buenas tiendas de comerciantes, propiamente mercaderes, que se surten principalmente de Málaga, algunos artículos de Granada y Sevilla, y han principiado a recibir también géneros directamente por conducto de los comisionistas franceses de las fabricas de Lion, traidos de Marsella, y de este punto a Málaga". Aunque no siempre con tanto detalle, se describe en el Diccionario de Madoz un importante comercio en Andalucía y de este caso concreto resaltemos algunos aspectos: la cantidad de productos, la red comercial, especialmente en Andalucía, y la importancia del puerto de Málaga como centro.

En el subbético sevillano Estepa, cabecera judicial con $7.339 \mathrm{~h}$, aparece en 1842 como un pueblo agrario con exportación de aceite y granos por medio de arriería, y sería, como hoy, el segundo centro comarcal de la Sierra Sur de Sevilla. En la montaña gaditana, Grazalema aparece como centro comarcal con casi 9.000 habitantes y una destacada fabricación textil (paños, bayetas), con tintorerías y máquinas de cardar, más curtidos y cordobanes, que emplean en total "unas 4.000 personas". Se exportaban "los géneros que se elaboraban para Cádiz, Sevilla, diferentes puntos de Andalucía y otras provincias". No lejos, y en el contacto con las campiñas de la cuenca del Barbate, Alcalá de los Gazules, 6.116 h., agraria y ganadera, tenía escasa función territorial ante la cercanía de Medina Sidonia, que era cabecera judicial. 


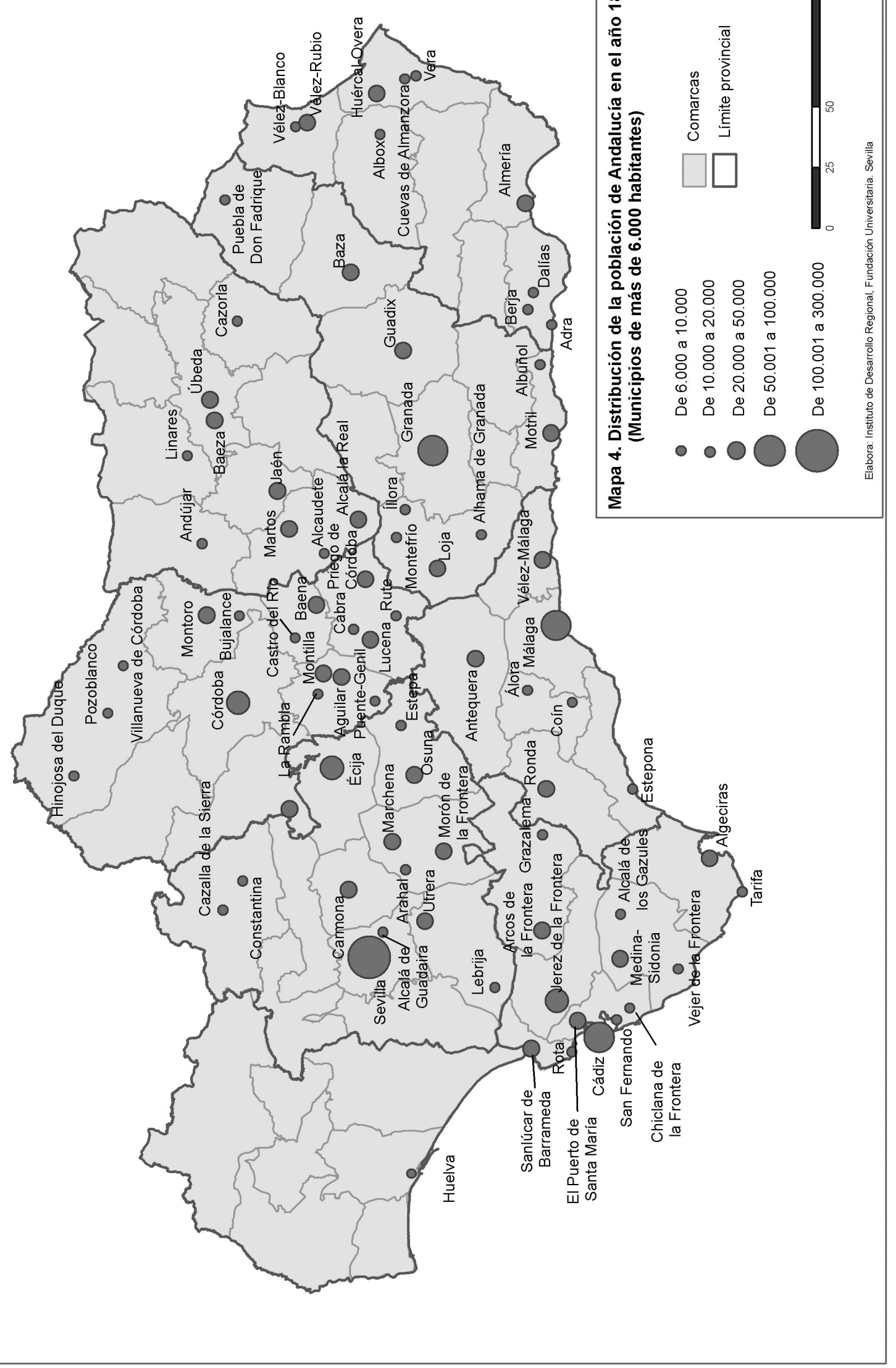




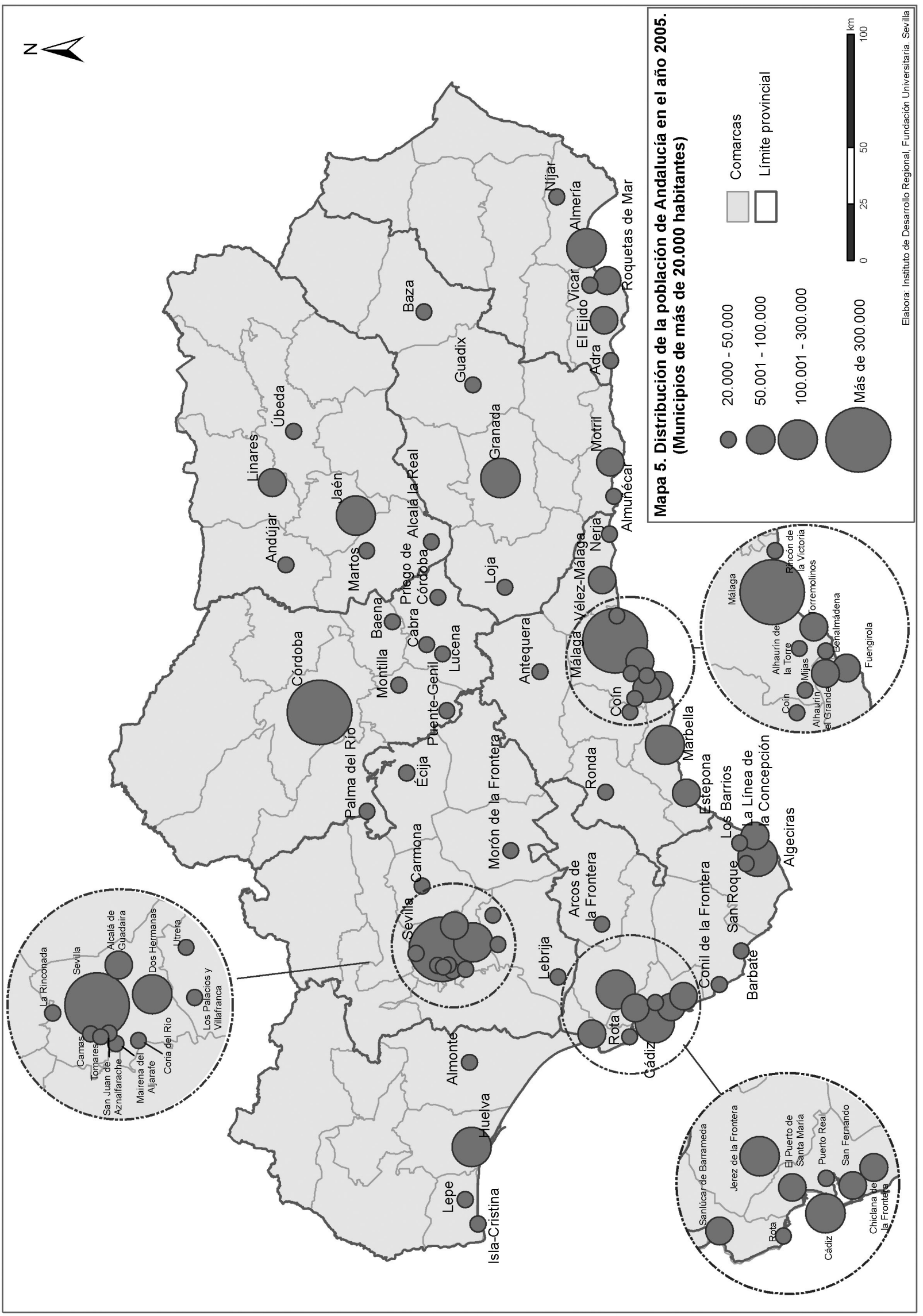




\subsection{Depresión Intrabética}

Vimos en los núcleos mayores de 10.000 (equivalentes territoriales de los superiores a los 20.000 de ahora) que este eje intrabético era bastante estable y dos de los tres que aparecen nuevos (6-10.000) lo ratifican, porque son fundamentalmente centros necesarios para la época en relación con las distancias. La Puebla de Don Fadrique $(6.154$ h.) se halla al norte de la provincia de Granada, cerca del límite con Murcia en una llanura agraria un tanto fría y árida, apta para cereales, ganado, explotación de aromáticas y de esparto y exportación de lana, muy apreciada en centros industriales como Alcoy. No era cabecera de partido judicial (sino Huéscar, algo más centrada en la comarca, aunque con menos habitantes, 5.759). Sin embargo, Vélez Blanco, de similares características y con 7.000 h., está próxima a la capital judicial de Vélez Rubio, ya analizado.

Después no hay ningún pueblo de esta categoría en la ruta Baza, Guadix, Granada hasta Alhama (6.284 habitantes) al sur de Loja, aunque a distancia. Era centro judicial, con unos baños termales de origen árabe, agricultura de la trilogía mediterránea, leguminosas y algunas huertas, además de "todos los oficios mecánicos de primera necesidad". En los tres núcleos de la Depresión, y como constante del momento, los caminos eran malos en Andalucía.

\subsection{La Costa}

La presencia de 12 núcleos costeros, o próximos al litoral, de 6-10.000 habitantes atenúa bastante el amplio espaciamiento visto en el grupo superior a 10.000. Hay que destacar en primer lugar la presencia de Huelva, cuya capitalidad (1833) aún no había tenido consecuencias importantes. En efecto, contaba sólo con 7.416 habitantes y un puerto, que se define como seguro refugio de la costa entre Trafalgar y Santa María por su barra litoral, pero de tráfico escaso, pues en el bienio 1844-45 se registraron un total de 11 buques, con entradas y salidas, sumando 554 toneladas y 73 tripulantes, embarcando principalmente naranjas, palma para escobas y trigo. No obstante, la matrícula era de 600 barcos de cabotaje entre 40 
y 200 toneladas, que operaban por la costa de Levante, África, y algunos hacían la carrera de América. Todo un barrio se dedicaba a la pesca en más de cien botes pequeños ("cuyo pescado bastante sabroso se vende con preferencia en Sevilla") y varias personas recolectaban mariscos, abundantes en los dilatados bajos. Ligado al puerto había 4 o 5 astilleros, pero la industria era escasa (cordelería, redes, harina), así como la producción de trigo, cebada y otros granos, vino y aceite, "que apenas bastan para el consumo"; más algún ganado vacuno y caballar en los pastos de las marismas, lanar y cabrío. La perificidad de Huelva se ve aumentada por las malas comunicaciones, pues los caminos eran todos "de herradura y aunque transitan carros, carecen de arrecifes y lo hacen con dificultad especialmente en invierno. Recientemente se ha aprobado por el gobierno una carretera con dirección a Sevilla". Después, según estudia MÁRQUEZ DOMÍNGUEZ, 1995, Huelva "ofrece un puerto de expolio a minerales, que 30 siglos antes fueron motivo de una renovación comercial y, ahora, son utilizados en la industria europea".

En torno a la Bahía de Cádiz, y como consecuencia principalmente del comercio con América en el XVIII, se localizan tres núcleos con más de 6.000 (Rota, San Fernando y Chiclana), que ahora pasan de los 20.000 y que, salvo Rota, eran cabeceras de partido judicial. Precisamente ésta por distancia a la "insular" capital podría tener entonces, y ahora, una mayor función como centro comarcal. Censaba 7.997 pobladores y tenía "un muelle de buena fábrica", por donde se exportaba fundamentalmente pipas de vino ("la célebre tintilla de Rota"), que era la principal producción.

San Fernando, como dijimos, había pasado de 28.138 en 1787 (por instalaciones militares) a 9.792 en 1842, si bien "de otros datos más verídicos resulta que entre la ciudad, San Carlos, Casería de Osio y arsenal de la Carraca, se reunen sobre 2.500 vecinos"; es decir, unos 12.500 habitantes. No obstante, preferimos incluirla a todos los efectos según el Censo de 1842 para que se note más la diferencia respecto a finales del XVIII, ya que en el Diccionario de Madoz se alude repetidamente a la decadencia de la ciudad por tres razones principales: la desaparición de barrios 
enteros tras la superpoblación por el refugio de gaditanos, gobierno y ejército con motivo de la guerra napoleónica; "el enormísimo censo que pagan todos los terrenos además de las contribuciones"; y, sobre todo, "el enorme atraso que por tantos años consecutivos sufrieron las clases de marina en la percepción de sus haberes, y la disminución que han tenido todos sus cuerpos por la lamentable decadencia". Se incluye un cuadro sumamente significativo, donde se comparan entre 1827 y 1841 casas productibles (de 2.625 a 1.371), tiendas de comestibles y bebidas (205 y 66), almacenes de grano (20 y 3), puestos de carne y chacina (32 y 14), y otros.

Porque la antigua Isla de León era una plaza militar (fortificada "por naturaleza y arte") con mando de teniente coronel, sede del departamento de Marina "que se titula de Cádiz", con arsenal (La Carraca), caserío de provisiones de víveres, cuarteles de artillería de marina, colegio naval para aspirantes, capitanía general, intendencia, contaduría principal, juzgados y demás dependencias, siendo también distrito de la nueva división de Comisarías. El Observatorio Astronómico ("el único establecimiento de esta clase en España y como los mejores de Europa") ocupa una densa página del Diccionario con descripción de los dos edificios e instrumentos. Por lo demás, la principal producción era la salinera con un sistema de compuertas, depósitos y tajería, dependiente en parte de la Hacienda real con casi 400.000 fanegas de producción, "que expende a todos los pueblos de España a 52 reales", lo que seguramente bastaba y sobraba para la nóminas. Y las salinas privadas alcanzaban unos dos millones de fanegas, vendidas "con mucho crédito al extranjero", dando ocupación esta actividad a 500 familias y a unas 200 en la pesca, "abundantísima y de gusto delicados", sobre todo la de los esteros. Había viñas, huertas y pocas tierras de labor más cinco fábricas de curtidos (para los pueblos inmediatos) y alguna otra fabricación (cristales, alimenticias...), alguna (tres molinos harineros) aprovechando como energía las crecientes y variantes del mar.

Algo menos próxima a Cádiz estaba Chiclana, rehecha tras la ocupación gala, donde en la segunda mitad del siglo XIX, la gente adinerada y la nobleza, sobre todo de la capital, vuelven a hacer de esta localidad su lugar de vacaciones y de curas, en los balnearios de Braque y de Fuente Amarga. Se produjo también por entonces un gran relanzamiento de sus vinos, según las noticias recogidas en el Diccionario de Madoz, hacia 1845, y se producían unas 100.000 arrobas de vino, exportado en su mayoría a América, existiendo 25030 bodegas, Aunque Tarifa pertenecía al 
partido judicial de Algeciras, distaba lo suficiente de ella, según los malos caminos de entonces, como para constituir un centro de cierta importancia (8.116 habitantes), producción agrícola y ganadera, y un pequeño tráfico portuario de unos 250 buques entrados y salidos al año con unas 4.000 toneladas totales. A unos 10 kilómetros de la costa, Vejer de la Frontera (9.144.h.) era residencia de un Ayudante comandante de Marina y de un vicecónsul de Francia, Inglaterra y Holanda, aunque su economía era agraria (casi toda de secano) y ganadera, aprovechando prados, naturales y artificiales, pastos y dehesas.

Mejor situación tenía Estepona, único centro entre Algeciras y Málaga, cabecera judicial de 8.088 habitantes y dibujada por el Diccionario de Madoz como bastante próspera. En la agricultura destacaban las viñas, "roturándose continuamente nuevas tierras que destinan a este plantío... de que se forman buenos vinos y pasas", siendo éstos las principales cosechas (8.000 arrobas y 1.500 quintales, respectivamente), seguidos de naranja, limón y batatas. La ganadería era escasa, no así la minería (hierro, amianto), la pesca (anchoba, arenque boquerón, sardina, caballa, atún...) y la industria (fundiciones, cerámicas, pieles), además de otros oficios. El comercio era considerable, tanto por la arriería, a la que se dedicaban una parte de los vecinos, como por la navegación (" en el que es mucho el arrojo y práctica que tienen sus naturales"), mediante 80 barcos costaneros y 500 marineros, que visitaban los puertos del Mediterráneo y el Atlántico hasta Huelva. El comercio interior se componía nada menos que de cien tiendas de abacería, y el puerto registró en 1843-44 una media anual de 177 entradas de barcos (tejidos, cuero, arroz, azúcar) y 157 salidas (pescado salado, cítricos, corcho, higos, pasas, loza, madera...). Y una consideración final para este mediado del XIX: "De modo que todo le hace ser un pueblo laborioso e industrial, con muy corto número que dependan del solo recurso de sus brazos, y así es que en la agricultura se ejercitan muchos jornaleros forasteros, de que procede en gran manera el aumento de su población y riqueza, pudiéndose formar idea de su progreso, por la observación de que hace muy poco mas de un siglo, no pasaba de 600 vecinos" (2.400 habitante, si aplicamos el índice de 1842).

En la Costa subtropical granadina estaba Albuñol (cabecera judicial de 6.764 pobladores), dedicados a la agricultura (sobre todo la vid), arriería, tejidos de lienzo "y a los demás oficios necesarios para la vida". El espíritu (para beneficio de los vinos de Jerez), el vino y las pasas eran los principales embarques en el puerto de la Rávita, dependiente de Motril (habiéndose solicitado el establecimiento de aduana 
propia). Esto suponía un gran perjuicio para los cargadores, al tener que despachar las guías a siete leguas del pueblo, cuestión que pone de manifiesto la importancia de las distancias y la necesidad de tenerlas en cuenta como un factor más a la hora de explicar los centros y los territorios. Adra era otro puerto importante, con 7.400 habitantes (la ciudad de Almería tenía 17.800), en cuya vega se cultivaban frutas, almendras, trigo y vides y, sobre todo, especies subtropicales, batata y caña de azúcar, elaborada en el Ingenio de Azúcares, espacioso edificio que se describe en el Diccionario de Madoz, si bien se constata ya la competencia del azúcar cubano.

La producción más importante entonces era la fabricación de metales, sobre todo plomo, en modernas fundiciones, propiedad de "D. Manuel Agustín Heredia, del comercio de Málaga, por compra hecha en 1837 a los señores Collmann, Lambert y compañía del comercio de Londres". Era la Fábrica Grande, denominada después de Heredia, con 10 hornos ingleses y personal especializado, a la que se une la llamada de los Hortales y La Amistad, con seis hornos más; todos ellos descritos profusamente por Madoz. Se producían planchas, caños y tubos de plomo, balas, perdigones, plata...A la agricultura y la industria, se suma una actividad portuaria considerable con 127 buques matriculados y la residencia, nada menos, que de vicecónsules de Francia, Bélgica, Suecia y Noruega. Además de la pesca, en el año 1842 se registraron con el extranjero 119 entradas de buques (con un total de 9.181 toneladas y una tripulación de 830) y unas salidas de 136 (10.636 y 968, respectivamente). Las cifras de cabotaje fueron ese mismo año de 298 buques entrados (11.270 toneladas) y 117 salidas. La exportación al extranjero se valoró en once millones de reales (y la de cabotaje, 5.5 millones más), consistente en 123.710 quintales de plomo y 21.240 de alcohol (mena de plomo argentífero), sobre todo a Marsella; 22.310 marcos de plata en barra y pasta; 16.639 arrobas de vino del país (de las Alpujarras), y frutos y otras producciones. A la decadencia posterior de esa industria se intenta hacer frente con la construcción del puerto en 1911 y la creación de la "Azucarera de Adra" (1911-1972) para basar más tarde su economía en la agricultura bajo plástico y el turismo.

Al pie de la Sierra de Gádor y a unos $15 \mathrm{~km}$ de Adra se hallan otros dos núcleos con más de 6.000 , Berja y Dalías (8.709 y 9.000 habitantes, respectivamente), con cierto auge entonces por la minería, que en la primera ocupaba de 150 a 200 operarios y daba lugar a importantes fundiciones (sobre todo, Mina de Berja y Loma del Sueño). Había algunas abandonadas por falta de leña, lo que era más grave en Dalías (por la casi desaparición del encinar debido al consumo de los hornos). 
Existía una producción agraria con fuerte demanda interna; arriería hacia Adra y la rada de Roquetas para la exportación de plomo y alcoholes; Berja era capital judicial, incluyendo a Adra, por su mejor situación entre la costa y las Alpujarras; y en la playa de Balerma (del término de Dalías) había una aldea de pescadores, y en verano "concurren infinitas familias a tomar los baños de mar, formando chozas o ranchos". Al norte de la provincia hay que citar a Vera (10.000 h.), que tenía una aldea, Garrucha (segregada en 1861), en la costa con un tráfico portuario de unos 770 buque anuales, sumando entradas y salidas, y $30.000 \mathrm{tm}$.

\subsection{Sierra Morena}

Una incorporación importante al sistema urbano andaluz de mediados del XIX lo constituyen cinco núcleos serranos. Más concretamente, tres agrociudades de los Pedroches (no propiamente Sierra en términos geomorfológicos, sino una penillanura sobre litología mariánica), Hinojosa del Duque, Pozoblanco y Villanueva de Córdoba (con términos pro indiviso con las otras tres villas de la Comarca), y dos centros, Cazalla y Constantina, en la Sierra Norte de Sevilla. Los tres primeros $(7.748,6.748$ y 6.572 , respectivamente) tenían buenas producciones, sobre todo de cereal, un cierto crecimiento de la vid (y del olivar, especialmente en la segunda), importante ganadería (en la primera, por ejemplo 20.000 ovejas), sobre todo piaras de cerdo de montanera, oficios artesanales (tejidos en Pozoblanco, principalmente) y comercio. También conviene mencionar que esta última era cabecera judicial, en el centro del eje y del camino hacia Córdoba ("hoy intransitable en su totalidad") y, desde luego, verdadera capital comarcal. Contaba con hospital, casa de maternidad, pósito, escuelas públicas con unos 400 alumnos, cátedra de latinidad, colegio de enseñanza superior y una buena feria en septiembre con toda clase de ganados y artículos.

Constantina (6.983 h.) es una ciudad serrana (pero de poca altura, que apenas modifica el clima mediterráneo) con agricultura de la trilogía clásica, exportándose, por medio de "un gran número de carretas" a Extremadura y Andalucía, vino, aguardiente, aceite y madera de castaño. Cazalla (6.552) era cabecera comarcal y tenía producciones similares, aunque con un aguardiente más conocido, que toma el nombre del propio pueblo. Sin embargo, destaca sobremanera en el Diccionario de Madoz las fundiciones de hierro de El Pedroso (aunque el municipio, $1.525 \mathrm{~h}$. ya existía). Las bases naturales eran las minas, la existencia de combustible (carbón y abundante vegetación, alguna repoblada) y la energía hídrica (Rivera del Huesna y Arroyo de San Pedro). La sociedad estaba formada por comerciantes sevillanos y 
se habían logrado unos sistemas y una tecnología avanzada para la época. Existían dos presas para almacenamiento todo el año con 59 pies de caída, que movían seis ruedas hidráulicas ("y otra que va a construirse"), una de las cuales "es de lo mejor de su clase que se conoce en Europa, y tiene 33 pies de diámetro, 4.5 de espesor y fuerza de 30 caballos". Los canales eran de hierro colado, había grúas de carga y hornos, "que se alimentan con sus propios gases", alcanzando temperaturas de 300 ${ }^{\circ} \mathrm{C}$; y se había aprobado la construcción de una máquina de vapor. La producción de hierro colado era de 50.000 quintales anuales, 4.000 en piezas moldeadas ("y otros efectos para la fábrica y el comercio", consumiendo una parte la fundición de artillería de Sevilla) y 20.000 de hierro fino con pedidos en aumento desde Sevilla, Cádiz, Córdoba, Valencia, Barcelona, Alicante, Madrid y Extremadura. Había unos 160 empleados fijos más la actividad inducida de combustible, carpintería, ladrillería refractaria, transporte...

\subsection{Otros}

Fuera de esas unidades 0 regiones andaluzas hay otras dos áreas para analizar: los valles del Guadalhorce, en Málaga, y del Almanzora, en Almería. En el primero se ubican dos centros agrarios con especialización, en el caso de Coín (8.239 habitantes y cabecera comarcal), en uva de Loja (que se exporta al extranjero desde Málaga) y en la recogida de esparto, goma y leña de la sierra ("pues prefieren su entera libertad a servir a sueldo de otros"). Y Álora (6.794 h.), que exportaba naranjas, pasas, vino, almendras, aceitunas, aceite y cáscaras de naranja agria.

En el Almanzora se sitúa Cuevas (10.000), cabecera de partido judicial, pero demasiado cerca de Vera para tener un área de influencia territorial, a diferencia de Albox (7.425), más centrada en el Valle y, hoy, una de las cabeceras de la Comarca. La agricultura era la principal ocupación con la trilogía mediterránea, pero también cultivos textiles, recogida de esparto (se trata de una zona árida), hortalizas y frutas (llevadas "hasta a Madrid", con especial mención de los higos), más alguna industria, significándose Albox en la fabricación de colchas, lienzos, mantelería "para el país", en 400 telares. Y en Cuevas de Vera destacaba la minería, "que ocupa millares de brazos, hasta extranjeros", con algunas fundiciones en Villaricos (donde había casas de veraneo), Palomares y Tarahal, lo que debía proporcionar un alto nivel económico, pues el comercio (destacaba también la arriería en estas comarcas limítrofes con Murcia) "es de lo mejor de su clase, y los géneros de vestir se importan de Barcelona, 
Marsella y otros mercados importantes; igualmente se hace especulación en el cambio y venta de las acciones de minas".

\subsection{El significado terrirorial de los núcleos mayores de 6.000 habitantes}

En la columna coincidente 1842-2005 (catorce núcleos), el carácter de centro comarcal actual no es lo más frecuente. Alcalá de Guadaíra es ahora parte del área metropolitana de Sevilla; al igual que San Fernando y Chiclana respecto a Cádiz y, con menos nitidez, Arahal, dentro de la Campiña y próxima por autovía a Sevilla. Aún más, Estepona y Adra son ahora centros secundarios de Marbella y El Ejido, respectivamente; mientras que Cabra y Coín comparten actualmente centralidad con otras ciudades. Según lo analizado antes, y a la vista del cuadro siguiente, procede distinguir varios grupos en el resto.

Aparecen ahora 22 núcleos en la costa (alguno no estrictamente, como los dos Alhaurín) con más de $20.000 \mathrm{~h}$, que a mediados del XIX no llegaban a 6.000. Como dijimos en el apartado 5.7, es principalmente producto del turismo y la agricultura forzada. Por el contrario, dos relevantes ejes urbanos (y geográficos, en general), como el Subbético y la Depresión Intrabética, presentan cinco y dos núcleos, respectivamente, que han disminuido en importancia relativa, porque eran fundamentalmente agrarios y no estaban a suficiente distancia de núcleos más importantes. Concretamente Vélez Blanco y Puebla de Don Fadrique tienen hoy otros centros, mientras que Estepa y Grazalema comparten capitalidad comarcal. También en Sierra Morena resaltaban entonces más que ahora centros cordobeses y sevillanos; lo mismo que en los valles del Almanzora y Guadalhorce.

El Valle del Guadalquivir presenta más variedad con tres columnas (cuadro 10) casi equivalentes: seis núcleos que han perdido importancia respecto a 1842 , por las mismas razones que en el Subbético; otros tantos que coinciden en ambas fechas, ya comentados, y diez, que obedecen mayoritariamente a la expansión del área metropolitana de Sevilla, más algunas transformaciones agrarias con nuevos regadíos: Almonte, incluido en el Valle por extensión, Palma del Río y, más cercanos a la capital, Los Palacios y La Rinconada. 
Cuadro 10. Comparación 1842 (Más de 6.000 h) y 2005 (Más de 20.000 h)

\begin{tabular}{|c|c|c|c|}
\hline & 1842 & 1842 y 2005 & 2005 \\
\hline \multirow[t]{5}{*}{ Valle Guadalquivir } & Alcaudete & Linares, Andújar & Palma Río \\
\hline & Bujalance, Castro, & Puente Genil & "Almonte" \\
\hline & La Rambla, Rute & $\begin{array}{l}\text { Arahal, Alcalá } \\
\text { Guadaíra }\end{array}$ & $\begin{array}{l}\text { Dos Hermanas, Los Palacios, } \\
\text { Coria }\end{array}$ \\
\hline & Alcalá Gazules & Lebrija & $\begin{array}{l}\text { Mairena Alj.,S. Juan Azn., } \\
\text { Tomares, Camas }\end{array}$ \\
\hline & & & La Rinconada \\
\hline \multirow[t]{4}{*}{ Subbético } & Cazorla, & Cabra & \\
\hline & Íllora, Montefrío & & \\
\hline & Estepa & & \\
\hline & Grazalema & & \\
\hline \multirow[t]{2}{*}{ Depr. Intrabética } & Vélez Blanco & & \\
\hline & Puebla D. Fadrique & & \\
\hline \multirow[t]{10}{*}{ Costa } & & Huelva & Lepe, Isla Cristina \\
\hline & & $\begin{array}{l}\text { Rota, San Fernando, } \\
\text { Chiclana }\end{array}$ & Puerto Real,, \\
\hline & & & Conil, Barbate, \\
\hline & & & $\begin{array}{l}\text { San Roque, La Línea, Los } \\
\text { Barrios }\end{array}$ \\
\hline & & Estepona & Marbella, Fuengirola, \\
\hline & & & $\begin{array}{l}\text { Benalmádena, Mijas, } \\
\text { "Alhaurín G" }\end{array}$ \\
\hline & & & "Alhaurín T", Torremolinos, \\
\hline & & & Rincón V., Nerja, \\
\hline & & & Almuñécar, \\
\hline & & Adra & Ejido, Roquetas, Vícar, Níjar \\
\hline \multirow[t]{3}{*}{$S^{a}$ Morena } & Hinojosa, Pozoblanco & & \\
\hline & Villanueva Córdoba & & \\
\hline & Cazalla, Constantina & & \\
\hline \multirow[t]{2}{*}{ Otros } & $\begin{array}{l}\text { Albox, Cuevas } \\
\text { Almanzora }\end{array}$ & & \\
\hline & Álora & Coín & \\
\hline
\end{tabular}




\section{LAS FUNCIONES URBANAS A MEDIADOS DEL XIX}

\subsection{La agricultura y las agrociudades}

La agricultura era la base de la economía de entonces y, como hemos visto, abundaba el secano (aunque también los huertos, y existían grandes vegas, por ejemplo Granada o Antequera), con la trilogía mediterránea, y además había leguminosas, textiles (lino, cáñamo y menos seda que en siglos anteriores), hortalizas y frutas; a veces, con singularidades como los melones de Sanlúcar o los peros de Ronda. Había tenido lugar una expansión del espacio cultivado desde el $30 \%$ de finales del XVIII al $50 \%$ a mediados del XIX (MARCHENA, 1989) con dos provincias periféricas (Huelva y Almería) de tan sólo el $20 \%$. La primera, por la mala calidad de los suelos (Sierra, penillanura del Andévalo 0 arenas de las tierras meridionales), que, junto con el efecto frontera y la marginalidad de comunicaciones, explica el solitario núcleo capitalino en el mapa. Y Almería, por la aridez, superada en los regadíos, sobre todo de los Vélez (con secanos más húmedos), Almanzora y Andarax, y la exportación de uvas. En el Diccionario de Madoz aparecen numerosas noticias de roturaciones, caso de Martos, por ejemplo (a veces ilegales, de los Propios municipales), ligadas a las desamortizaciones, que afectan más en realidad a la segunda mitad del XIX.

Las ricas campiñas de términos municipales extensos y propiedad concentrada potencian las agrociudades, de las que hemos visto tantas. Recordemos Écija, séptimo núcleo poblacional de Andalucía en 1842, que producía 400.000 arrobas de aceite y otras tantas fanegas de trigo. El olivar aparece por doquier, especialmente en el subbético, menos apto para los cereales; y ya existían importantes zonas vitivinícolas, como Jerez (casi medio millón de arrobas al año), Montilla, Manzanilla de Sanlúcar, Tintilla de Rota, vino de Albuñol, aguardiente de Cazalla...Entre Adra y Vélez Málaga se extendían cultivos tropicales, sobre todo caña de azúcar, proveedora de una industria que desarrolla núcleos como Motril.

\subsection{La industria}

Era más abundante de lo que suele afirmarse, pudiéndose distinguir la de autoabastecimiento, local y comarcal, y la exportadora, basada principalmente en las dos locomotoras del desarrollo desde la revolución industrial, siderurgia y textil. La primera radicaba principalmente en Málaga y Sevilla, pero también en Marbella, 
El Pedroso, Cádiz o, en fundición de plomo, Adra. La textil estaba más dispersa: Sevilla, Cádiz, Málaga, Antequera, Ronda, Écija, Baena, Osuna, Albox, por citar algunos. Lógicamente, las buenas producciones agrarias, las malas comunicaciones y la tendencia autosuficiente dan lugar a una relevante industria agroalimentaria, también distribuida por ciudades y pueblos; sobre todo, de harina, aceite y vino, aunque contaban algunas específicas, como la azucarera de la costa subtropical - la fabricación tabaquera sevillana, con una distribución de mayor amplitud. Después había una serie de producciones de todo tipo, curtidos, cordobanes (como Grazalema), calzado (Guadix), madera, muebles (Cabra), metálicas, herramientas, loza (Cartuja de Sevilla), alfarería (Aguilar, Úbeda), jabón, astilleros en varios puertos (Sevilla, Huelva), el caso especial de las lámparas de Lucena, joyas (Córdoba, Cádiz), materiales para obtención y envasado de vinos y destilados, etc.

\subsection{Comercio y comunicaciones}

Como hemos indicado, había bastante economía autosuficiente local y comarcal, registrándose numerosas tiendas, así como mercados semanales. Pero también hay un comercio de más amplio radio, sea por ferias periódicas, sobre todo de ganado, sea por medio de arriería; y, a escala mayor, a través de cabotaje y exportación en los numerosos puertos andaluces. En efecto, desde Ayamonte a Garrucha, además del muelle fluvial de Sevilla, hay un considerable tráfico comercial, destacando Málaga, pero notable también en otros (Cádiz, Algeciras, Huelva...); a veces, por razones coyunturales, como el embarque de mineral. Se repite en el Diccionario de Madoz las carencias y dificultades de caminos y carreteras, y se hacen recomendaciones para su mejora, pensando en el comercio y, precisamente, en el enlace portuario. La arriería era una actividad importante (en algún lugar, la tercera, tras agricultura y ganadería) y se hace constar que en muchos sitios, especialmente en las tierras con excedentes, era el medio para transportar mercancías a embarcaderos y ciudades.

\subsection{Otras actividades económicas}

Se constatan otras funciones con menos repercusiones en el crecimiento urbano. La ganadería se menciona abundantemente, siendo famoso el caballo andaluz desde Baeza a las marismas. La pesca era más bien de mercado local y comarcal, mientras que las salinas eran muy importantes en San Fernando. La 
minería de mediados del XIX radicaba principalmente en las sierras de Gádor y Almagrera (explicando la existencia de varios centros en el Levante y Poniente de Almería). Sin embargo, en Linares había decaído algo, apenas comenzaban las del carbón en el norte de Córdoba, y las mayores producciones de Riotinto datan de la segunda mitad del siglo. El aprovechamiento forestal se basaba en la extracción maderera de las sierras de Cazorla y Cádiz, además de esparto y plantas aromáticas en las zonas orientales más áridas. Como dato curioso, hay que mencionar los veraneos en Chiclana y otros lugares (Cuevas de Almanzora, Aracena...).

\subsection{La administración y las cabeceras comarcales}

Sin duda, la administración es una función urbana importante, que implicaba a las capitales de provincia y, a otro nivel, a las cabeceras de partidos judiciales; pero ambas instituciones (1833 y 1834) apenas habían tenido tiempo de producir la acumulación, sobre todo en las primeras, de servicios de todo tipo con repercusiones demográficas y de crecimiento económico. Sí que destacan, como vimos, las dos grandes ciudades históricas de Andalucía: Sevilla y Granada. Y hemos comprobado, así mismo, que en algunas descripciones se cita, o se deduce, una cabecera comarcal con múltiple funcionalidad; sobre todo, de instalaciones comerciales, lo que da pie a un último epígrafe de este trabajo.

\section{CIUDADES Y COMARCAS}

Vamos a comparar los mapas cuatro (mayores de 6.000 en 1842) y cinco (núcleos con más de $20.000 \mathrm{~h}$. en el 2005) para añadir argumentos a la hipótesis sobre la posible equivalencia de ambos umbrales. En principio, destaca una distribución más regular en el XIX frente a los fuertes desequilibrios actuales, pudiéndose distinguir varios aspectos: primero, un mayor crecimiento en las capitales y algunas ciudades, sobre todo del litoral; segundo, la concentración de núcleos formando conurbaciones en algunos casos; tercero, el mantenimiento de los tres ejes urbanos interiores (Valle del Guadalquivir, Subbético y Depresión Intrabética); y cuarto, persistencia de una periferia poco urbanizada y desarticulada.

El aumento demográfico mayor (en ocasiones, espectacular, como vimos en algunos cuadros) de capitales y núcleos costeros es algo conocido; y se debe a la 
inmigración (primero, de corta distancia, y hoy, a escala mundial) por la atracción de las grandes urbes (servicios, oferta de empleo...), las actividades turísticas (con el añadido principal de la construcción) y la agricultura forzada. Ese incremento se nota principalmente en la costa y las capitales de provincia, más algún caso del interior, como Linares. La concentración de núcleos de demografía progresiva, formando áreas metropolitanas, es un fenómeno relativamente reciente (que añade a la atracción de los grandes núcleos la proliferación de ciudades dormitorios y urbanizaciones en pueblos de la periferia), conjugándose factores de escasez y carestía de suelos en los centros con la búsqueda de viviendas en horizontal en un ambiente "rural". Destacan ahora en este sentido las áreas de Sevilla, Cádiz-Jerez y Málaga-Costa del Sol. Y, si se incluyesen municipios de 10.000 a 20.000 habitantes, aparecerían tales aglomeraciones en la cartografía de otras áreas o comarcas capitalinas, excepto Córdoba, que enmascara la situación en un término municipal mayor.

En cuanto a la costa, existe una gran diferencia entre el casi continuo actual desde Almería a Ayamonte (con hiatos o menor intensidad, como el este del litoral granadino, Tarifa-La Janda y, sobre todo, Doñana) y los espaciados centros del XIX, con pauta similar en distancias y funciones a los ejes del interior. Cabe señalar que, excepto en la provincia de Huelva, todas las comarcas tienen en 1842 un centro al menos, lo que avalaría la equivalencia territorial y funcional de los umbrales que comparamos. Había dos comarcas almerienses con tres núcleos de 6.000-20.000 h., el Levante y el Poniente, destacando en la primera, como ahora, Huércal Overa en una zona de auge minero; y en la segunda, habría que inclinarse por Adra, a la vista de lo que conocemos. Otras dos comarcas costeras tenían sendos núcleos, aunque no existe duda de la prevalencia de Motril y Algeciras sobre Albuñol y Tarifa, respectivamente. Y, por último, el caso de la Bahía de Cádiz es especial, como antecedente de la conurbación actual.

Respecto al mantenimiento de los tres ejes urbanos interiores (Valle del Guadalquivir, Subbético y Depresión Intrabética), en el primero (y dejando aparte las capitales y el citado caso de Linares), las Campiñas no han ofrecido las condiciones suficientes como para que algunos núcleos de entre 6.000 y $20.000 \mathrm{~h}$. del XIX hayan sobrepasado hoy el umbral más alto. Son Montoro, Bujalance, Castro, La Rambla y Aguilar, en Córdoba; y Marchena y El Arahal, en Sevilla. Pero, desde un enfoque comarcal, salvo el caso primero, cabecera del Alto Guadalquivir y, quizás, Marchena, son pueblos de áreas con otras capitales comarcales (Baena, Montilla, Puente 
Genil). La bicefalia en 1842 de Úbeda-Baeza en la comarca de Las Lomas parece comprobado.

En el Subbético, no han llegado a superar los 20.000 h. ciertos centros comarcales de 1842: Cazorla, Alcaudete (en la comarca que encabezaba, al igual que hoy, Alcalá la Real), Rute (en el Subbético polinuclear), Estepa, Osuna (cabeceras, ambas de la Sierra Sur de Sevilla) y Grazalema (en la Sierra de Cádiz). El eje intrabético se mantiene bastante (Baza, Guadix, Granada, Loja y Antequera) con una equivalencia clara entre los dos umbrales en cuestión; pero hay tres comarcas que difieren en ambas fechas: Los Vélez (con prevalencia de Vélez Rubio), Huéscar (entonces con centro en Puebla de Don Fadrique) y el Poniente granadino, que añade a Loja dos subáreas ahora (comarcas en 1842 por las diferencias de tiempos de desplazamientos) Íllora y Montefrío, en los Montes, y Alhama, al sur.

En lo referente a la periferia, se ha agudizado la despoblación por efectos de la emigración, así como por la conocida concentración en costa y áreas metropolitanas. La ausencia en el 2005 de municipios mayores de 20.000 h., salvo en la costa, en la provincia de Huelva (sierras, malos suelos, crisis minera y frontera con Portugal), no se diferencia mucho del mapa de 1842 con una pequeña capital desde hacía sólo nueve años. Las comarcas de Sierra Morena y el Prebético, desde Aracena a Sierra de Segura (exceptuamos Andújar y Linares, con núcleo en el Valle), no tienen ahora cabeceras importantes; ni las tenían en 1842, excepto en la bicéfala Sierra Norte de Sevilla; mientras que el caso de la penillanura de los Pedroches (Hinojosa, Pozoblanco y Villanueva) se explica en el XIX por la importancia de la agricultura. En la Penibética, las sierras de Almería, Alpujarras, etc., carecen de centros importantes, salvo Ronda, cuenca intramontana en realidad. Restan por comentar los valles del Guadalhorce (con doble cabecera: Coín, en ambas fechas, y Álora) y Almanzora (con pérdida de importancia relativa de Albox, centro actual también). Lo mismo ha ocurrido con Medina Sidonia, Alcalá de los Gazules y Vejer, en la Janda; mientras que Arcos de la Frontera (hoy con más de 20.000 h.) se ha mantenido.

Esta consideración de núcleos en relación con las comarcas completa el análisis del sistema urbano y sirve para matizar las equivalencias de los dos umbrales propuestos, siendo más admisible en los centros comarcales de 1842, incluyendo algunos casos de doble cabecera. Y, por otra parte, ha servido también para recordar que hay comarcas del 2005 con cabeceras menores de 20.000 h., según hemos estudiado en otras ocasiones (1987, 2000 y 2002). 


\section{ALGUNAS CONCLUSIONES}

El crecimiento de los municipios urbanos entre 1842 y 2005 ha sido mayor que el correspondiente a la población total de Andalucía; sobre todo, en las capitales y su entorno, así como en el litoral. Los efectivos demográficos de los grandes ejes internos (Valle del Guadalquivir, Subbético y Depresión Intrabética) también han aumentado, aunque los cambios han sido menores, y los centros comarcales muestran una cierta estabilidad, apareciendo el sur cordobés como una importante área urbana polinuclear ya a mediados del XIX. En cuanto a funciones, las agrociudades (término específicamente andaluz, no por casualidad) eran en esas fechas una realidad muy nítida, ligada a campiñas, llanuras y valles de buenas producciones (características de clima, suelos...) y extensos términos municipales, que fuerzan un espaciamiento de núcleos, bien definidos, incluso amurallados. Eso contrasta con las conurbaciones actuales, en torno a las grandes ciudades (con límites municipales cada vez más artificiales), en un modelo más ligado al suelo (soporte para urbanizar) que a los recursos territoriales. Sin embargo, los servicios no dejan de serlo en realidad, y otras ofertas se han modificado, en cuanto a su influencia urbana, o han surgido nuevas, como las que potencian el litoral (clima, playas, cultura...).

Aunque el agro era la principal explicación de muchos asentamientos, no conviene generalizar, porque hemos visto cómo a mediados del XIX la industria repercutía en la importancia de algunas urbes, así como la situación portuaria, el comercio, las minas, etc. En cambio, una de las funciones más importantes en época moderna, la administración, pesa solo en las grandes urbes (especialmente, Sevilla y Granada), ya que la instauración de cabeceras provinciales (con tanta repercusiones posteriores) y judiciales databan de 1833 y 1834, respectivamente. En conjunto, el modelo urbano del XIX presenta una mejor distribución que la presente; incluso la minería serrana contribuía a potenciar centros en zonas periféricas, que hoy se hallan relativamente peor provistas de asentamientos por efectos de la emigración. Con todo, existían vacíos en Sierra Morena oriental, en las montañas penibéticas y, sobre todo, en la provincia de Huelva.

Recordemos que considerando urbanos a municipios desde 6.000 habitantes a mediados del XIX, según la hipótesis de establecer relación entre los umbrales (20.000 ahora) y la población total. Para comprobar esa posibilidad (uno de los objetivos del trabajo), hemos analizado, a través del Diccionario de Madoz, las funciones de los núcleos, y se han tenido en cuenta, además, otros aspectos, como las distancias y la 
existencia de cabeceras comarcales. Resulta que la inmensa mayoría de municipios entre 10.000 y 20.000 habitantes pueden considerarse urbanos (o, mejor, centros territoriales o comarcales), lo que no puede afirmarse (por lo que hemos visto) de todos los situados en el intervalo 6.000-10.000 h. Desde una óptica metodológica, parece clara la utilidad de usar como "laboratorio territorial" situaciones pretéritas para establecer diferentes modelos de organización espacial y comparar con los actuales.

\section{BIBLIOGRAFÍA}

ALMOGUERA SALLENT, P.: "Demografía Aplicada al Área Metropolitana de Sevilla", Espacio y Tiempo, no 17, 2003, pp. 29-64.

BARRAGÁN MUÑOZ, J.M.: La Bahía de Cádiz, Cádiz, Ayuntamiento, 1988.

BERNAL, A.M.: "Introducción a la Provincia de Sevilla", del Diccionario de Madoz, 1845-50, Edición de Sánchez Zurro, Editoriales Andaluzas Unidas, 1988.

BOSQUE MAUREL, J.: "Introducción a la Provincia de Granada", del Diccionario de Madoz, 1845-50, Edición de Sánchez Zurro, Editoriales Andaluzas Unidas, 1988.

CANO GARCÍA, G.: Geografía de Andalucía, Tomo VIII, Sevilla, Tartessos, 1987, pp. 205-259.

CANO GARCÍA, G.: Gran Enciclopedia Andaluza Tomo V, Sevilla, Tartessos, 2000, pp. 11-45.

CANO GARCÍA, G.: Comarcas Andaluzas Sevilla, Tartessos, 2002, pp. 11-85.

CANO GARCÍA, G y JORDÁ BORRELL.: Voces de municipios mayores de 20.000 habitantes en Gran Enciclopedia General de Andalucía, Málaga, Comunicación y Turismo, Editores. 2004-2007, 15 tomos.

CAPEL MOLINA, J.J.: "Introducción a la Provincia de Almería", del Diccionario de Madoz, 1845-50, Edición de Sánchez Zurro, Editoriales Andaluzas Unidas, 1988.

FERIA TORIBIO, J.M.: Los procesos metropolitanos, Sevilla, Centro de Estudios Andaluces, 2006. 
IGLESIAS RODRÍGUEZ. J.J.: El Puerto de Santa María, Cádiz, Diputación Provincial, 1985.

JUNTA DE ANDALUCÍA: Atlas de Andalucía. Tomo 4. Cartografía Urbana, Sevilla, 2000.

LACOMBA, J.A.: "Introducción a la Provincia de Málaga", del Diccionario de Madoz, 1845-50, Edición de Sánchez Zurro, Editoriales Andaluzas Unidas, 1988.

LÓPEZ ONTIVEROS, A.: "Introducción a la Provincia de Córdoba", del Diccionario de Madoz, 1845-50, Edición de Sánchez Zurro, Editoriales Andaluzas Unidas, 1988.

MADOZ, P.: Diccionario Geográfico-estadístico-histórico de España, Madrid, 18451850.

MARCHENA GÓMEZ, M.: "La superficie cultivada en Andalucía", Geografía de Andalucía, Tomo IV, Dir. G. Cano, Sevilla, Ed. Tartessos, 1989, pp. 109-146.

MÁRQUEZ DOMíngUEZ, J. A. (Dir): Los Pueblos de Huelva, Madrid, Ed. Mediterráneo, 1995.

OJEDARIVERA, J.: "Introducción a la Provincia de Huelva", del Diccionario de Madoz, 1845-50, Edición de Sánchez Zurro, Editoriales Andaluzas Unidas, 1988.

PARLAMENTO DE ANDALUCÍA: Comisión de Estudio sobre la población andaluza, Sevilla, RC Impresores, 2005, 150 pp.

SÁENZ LORITE, M.: "Introducción a la Provincia de Jaén", del Diccionario de Madoz, 1845-50, Edición de Sánchez Zurro, Editoriales Andaluzas Unidas, 1988.

SERRANO MARTÍNEZ, J.M.: Área Metropolitana de Murcia, Murcia, Universidad, 1993.

SUÁREZ JAPÓN, J.M.: "Introducción a la Provincia de Cádiz", del Diccionario de Madoz, 1845-50, Edición de Sánchez Zurro, Editoriales Andaluzas Unidas, 1988. 